\title{
Enantioselective Synthesis of Ring-Fused Spiroannulated 1,2,3-Thiadiazole Derivatives
}

Xue-Mei Zeng, Jian-Wu Xie*

Key Laboratory of the Ministry of Education for Advanced Catalysis Materials, Department of Chemistry and Life Science, Zhejiang Normal University, Jinhua 321004, P. R. China

\section{Supporting Information}

1. ${ }^{1} \mathrm{H}$ NMR and ${ }^{13} \mathrm{C}$ NMR spectra.

2.HPLC spectra.

3. X-ray data of enantiopure 


\section{1. ${ }^{1} \mathrm{H}$ NMR and ${ }^{13} \mathrm{C}$ NMR spectra.}

4aa
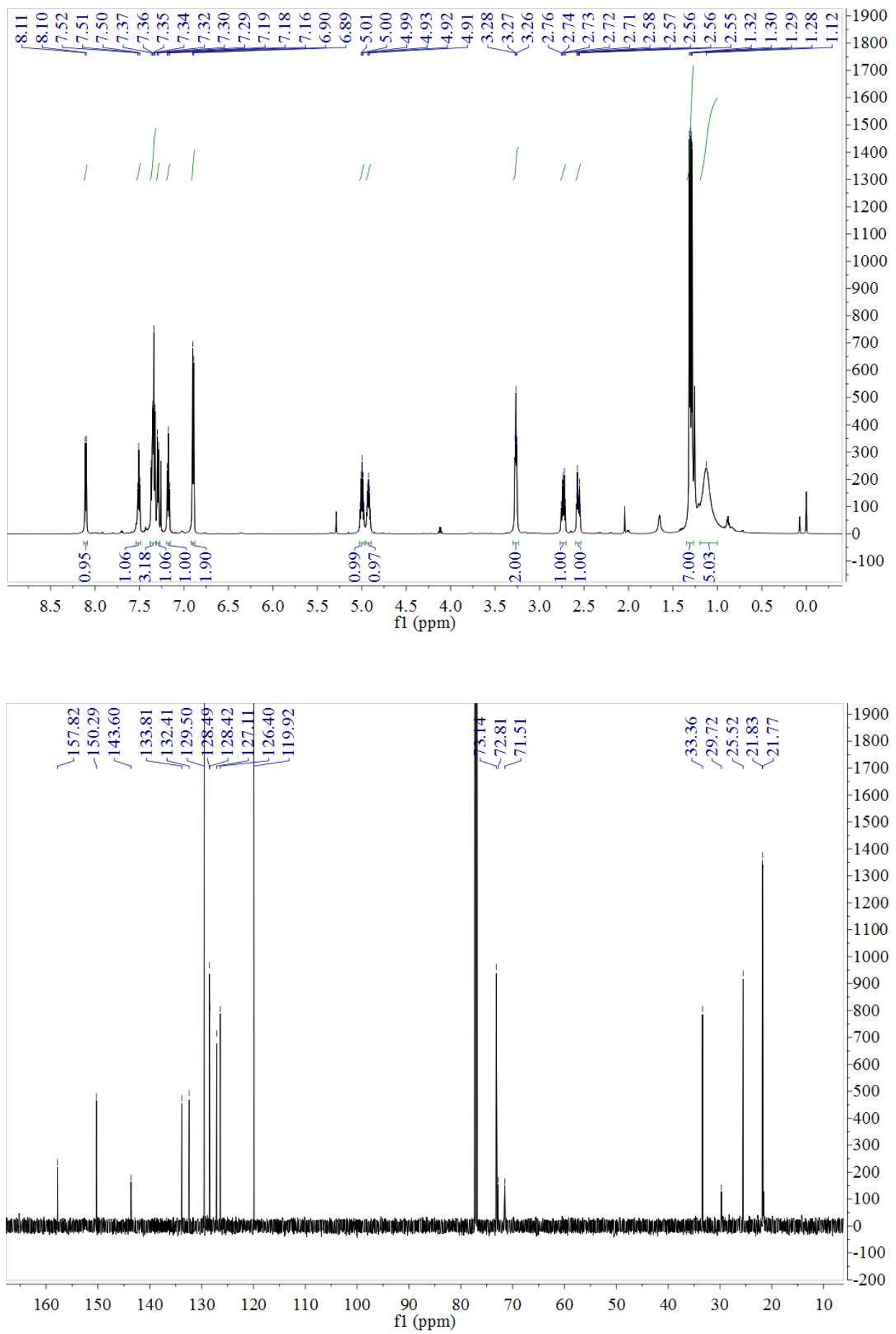


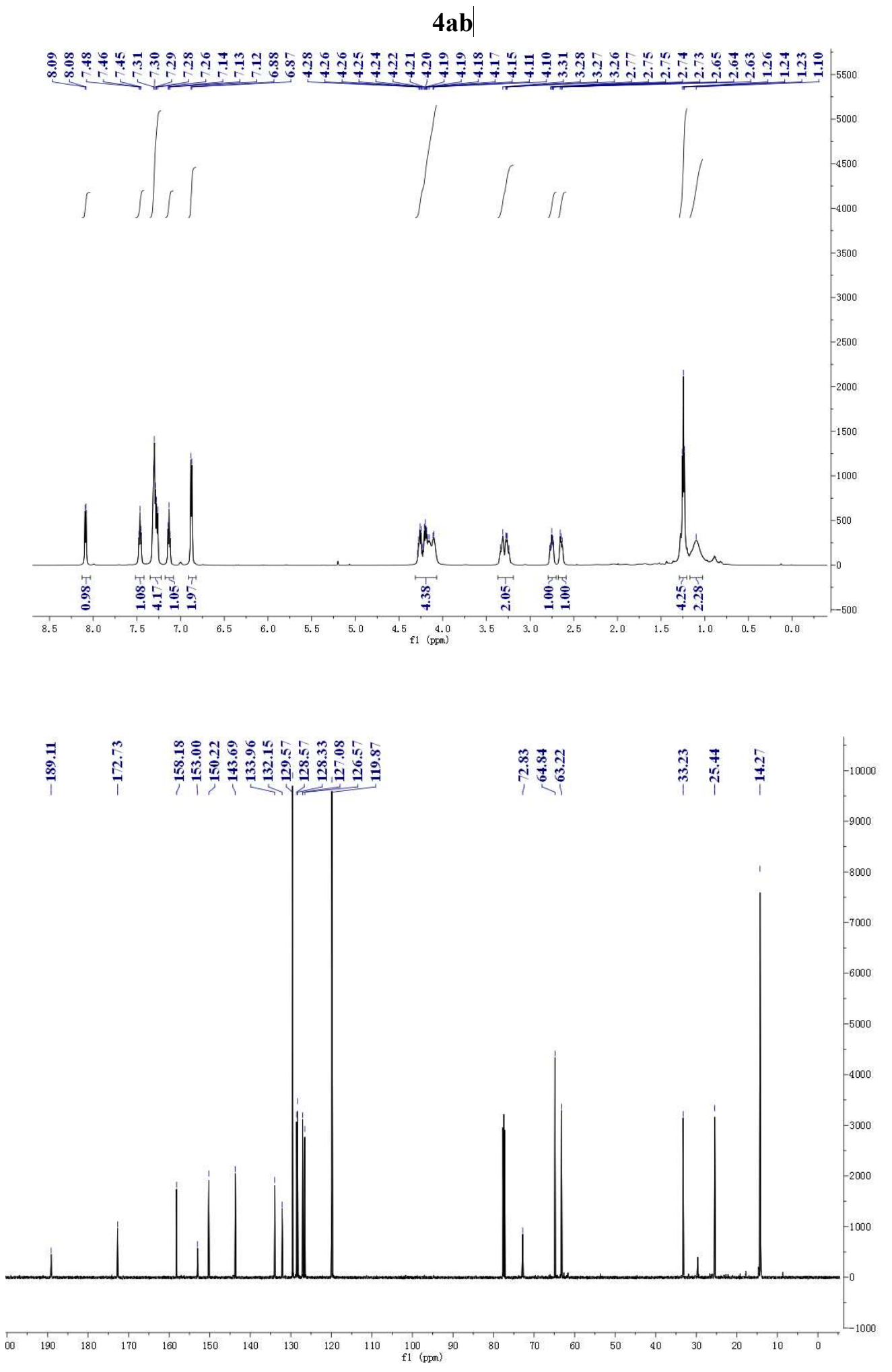


$4 a c$
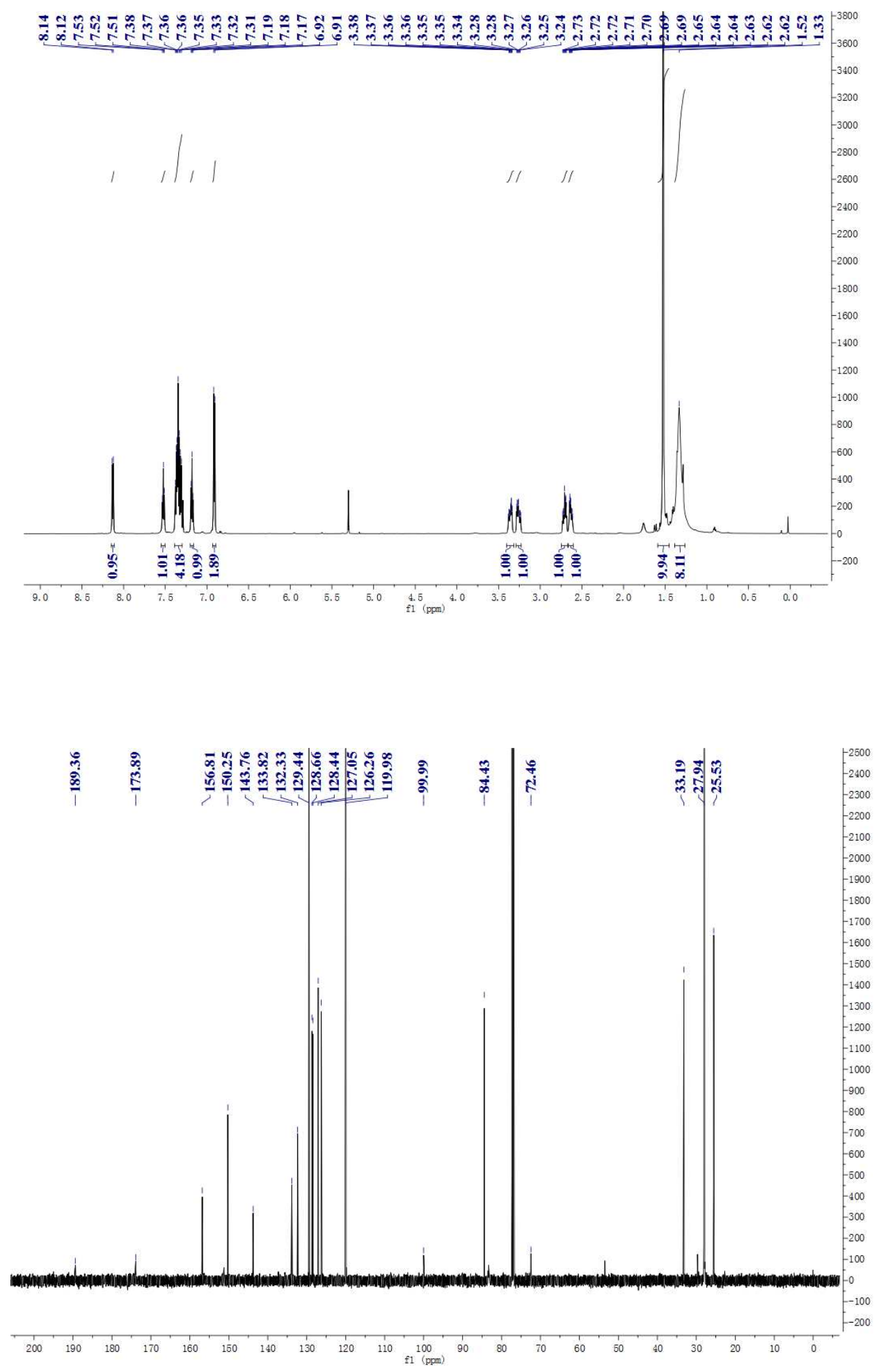
$4 \mathrm{ba}$
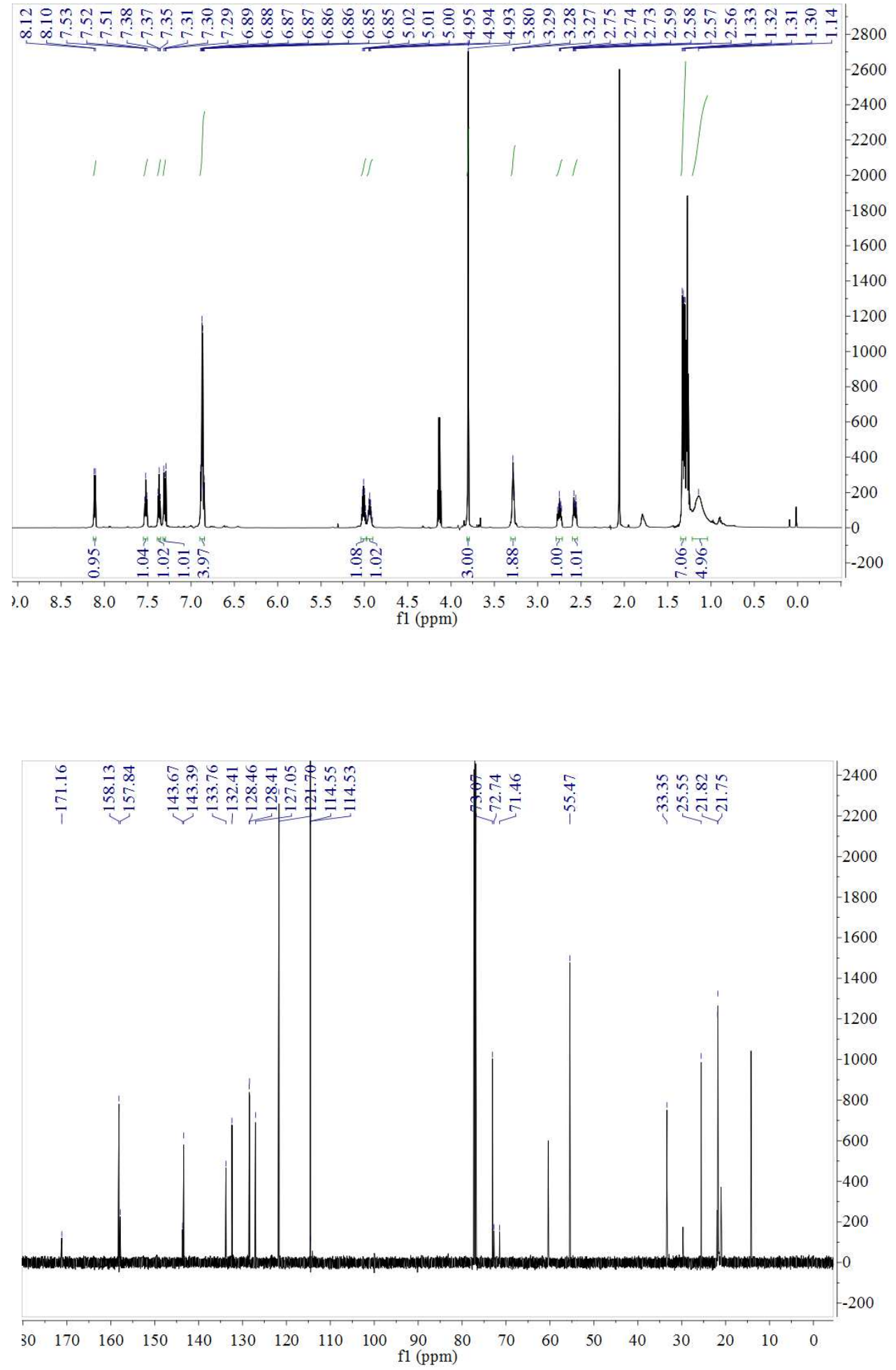
$4 \mathrm{ca}$
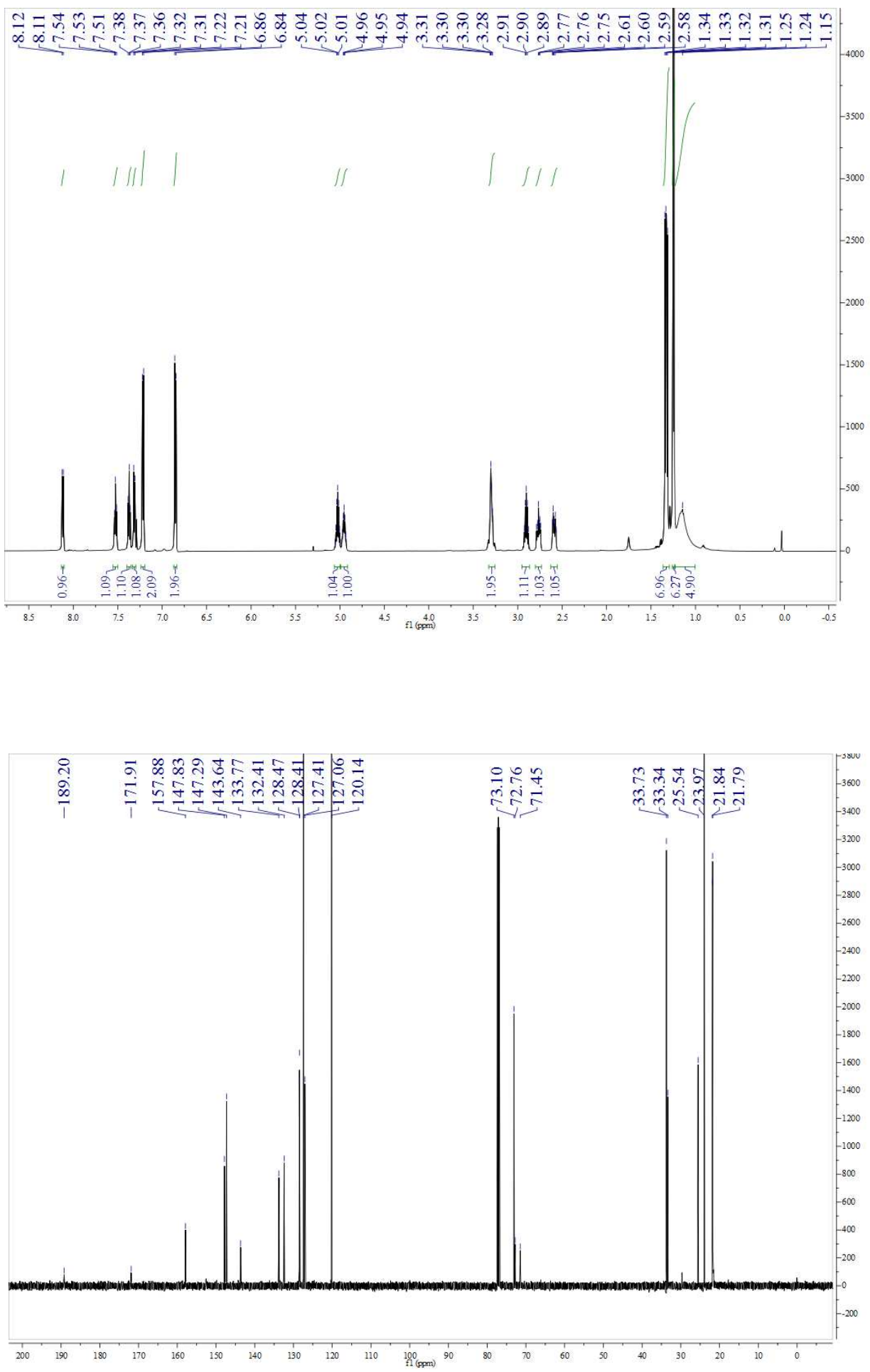
4da
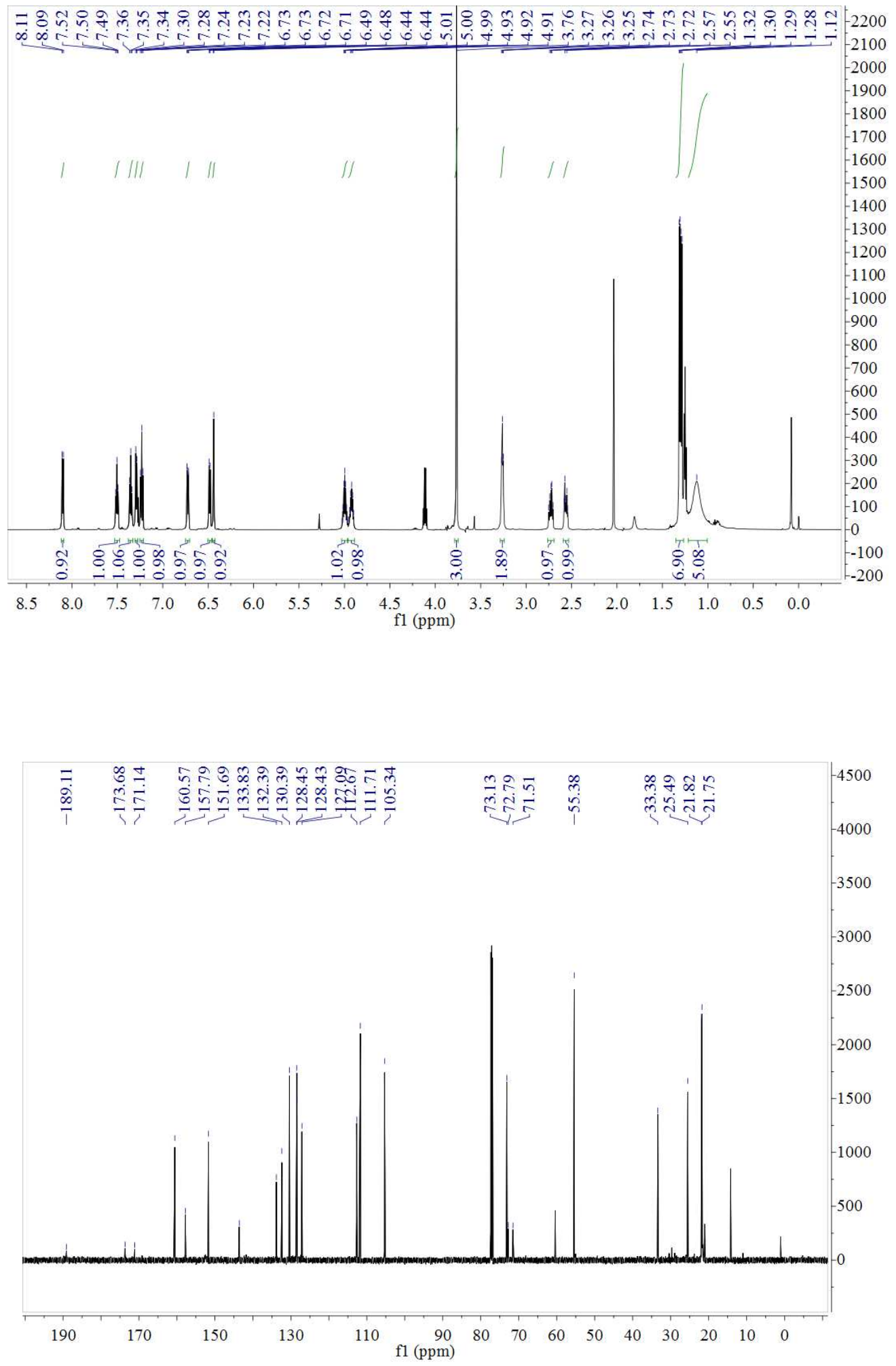
4ea
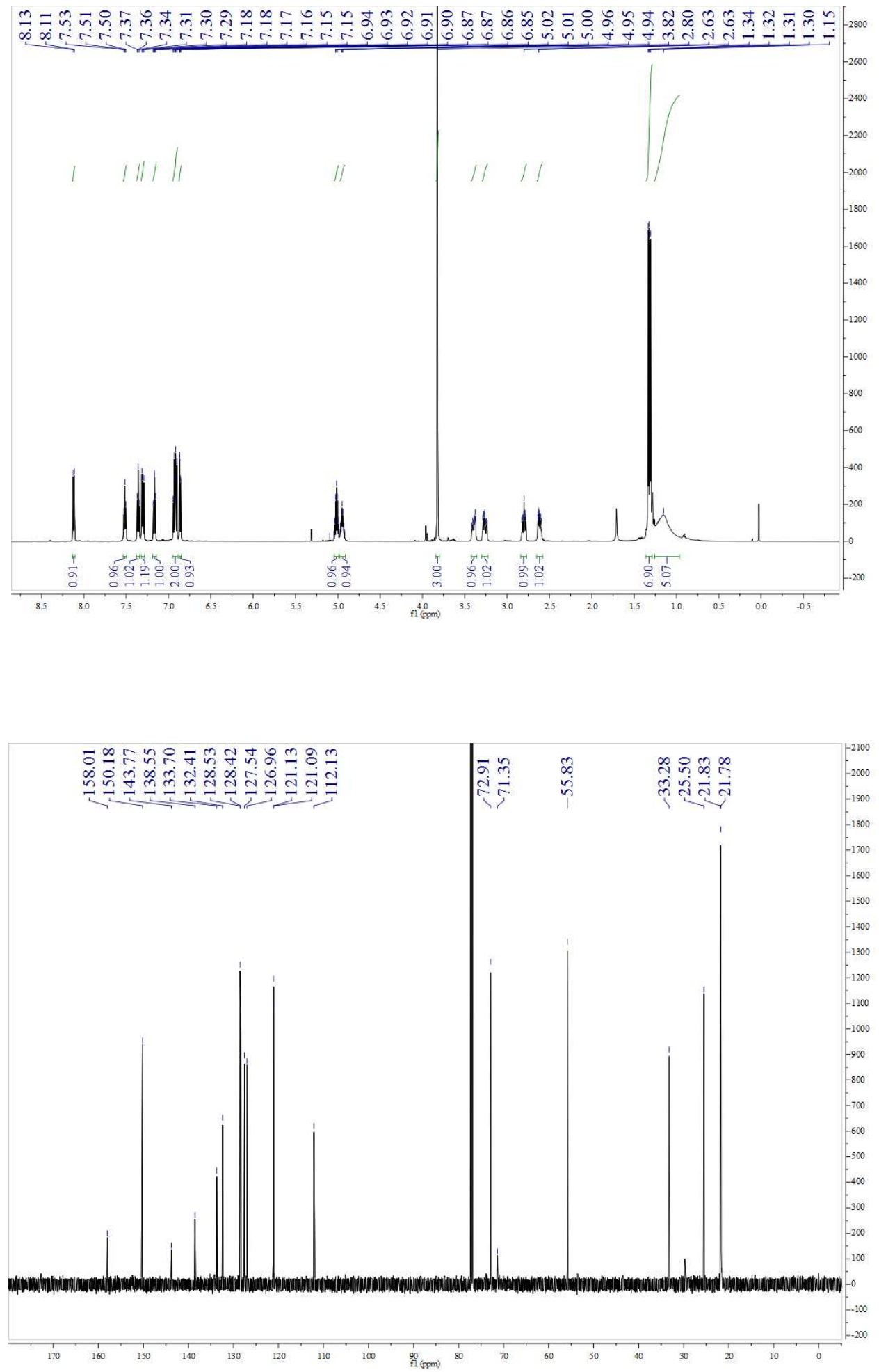
$4 f a$
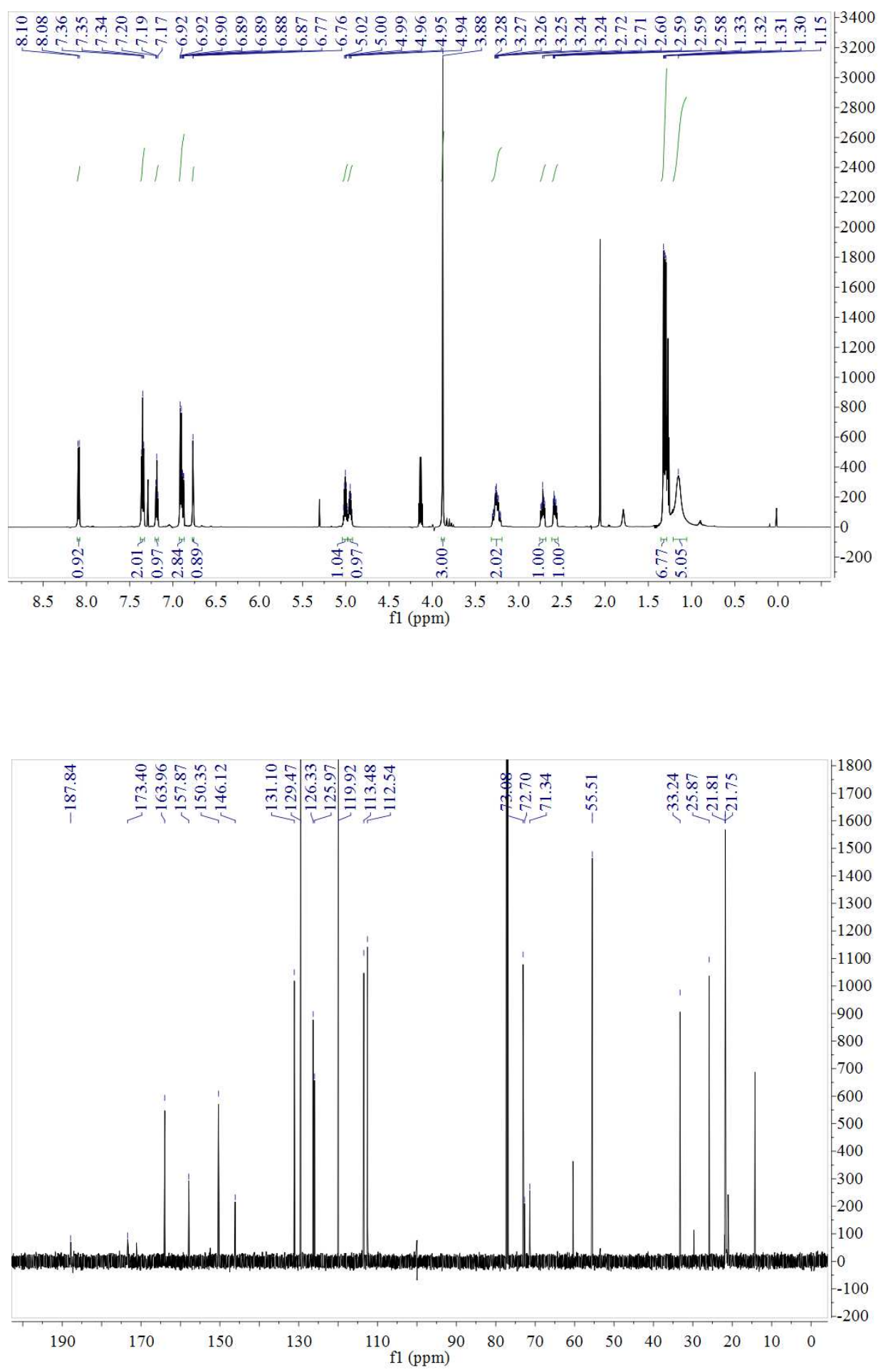

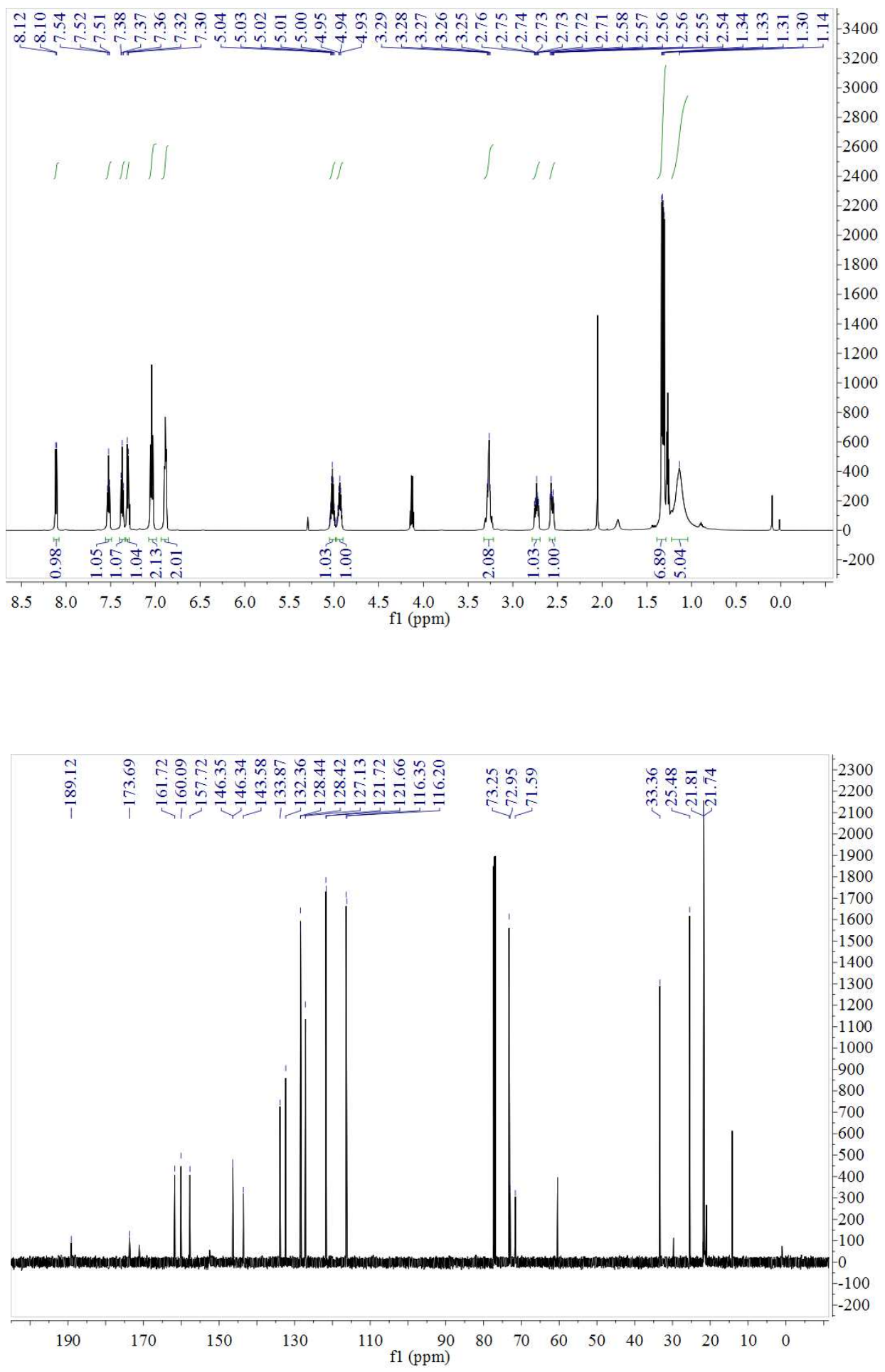
4ha
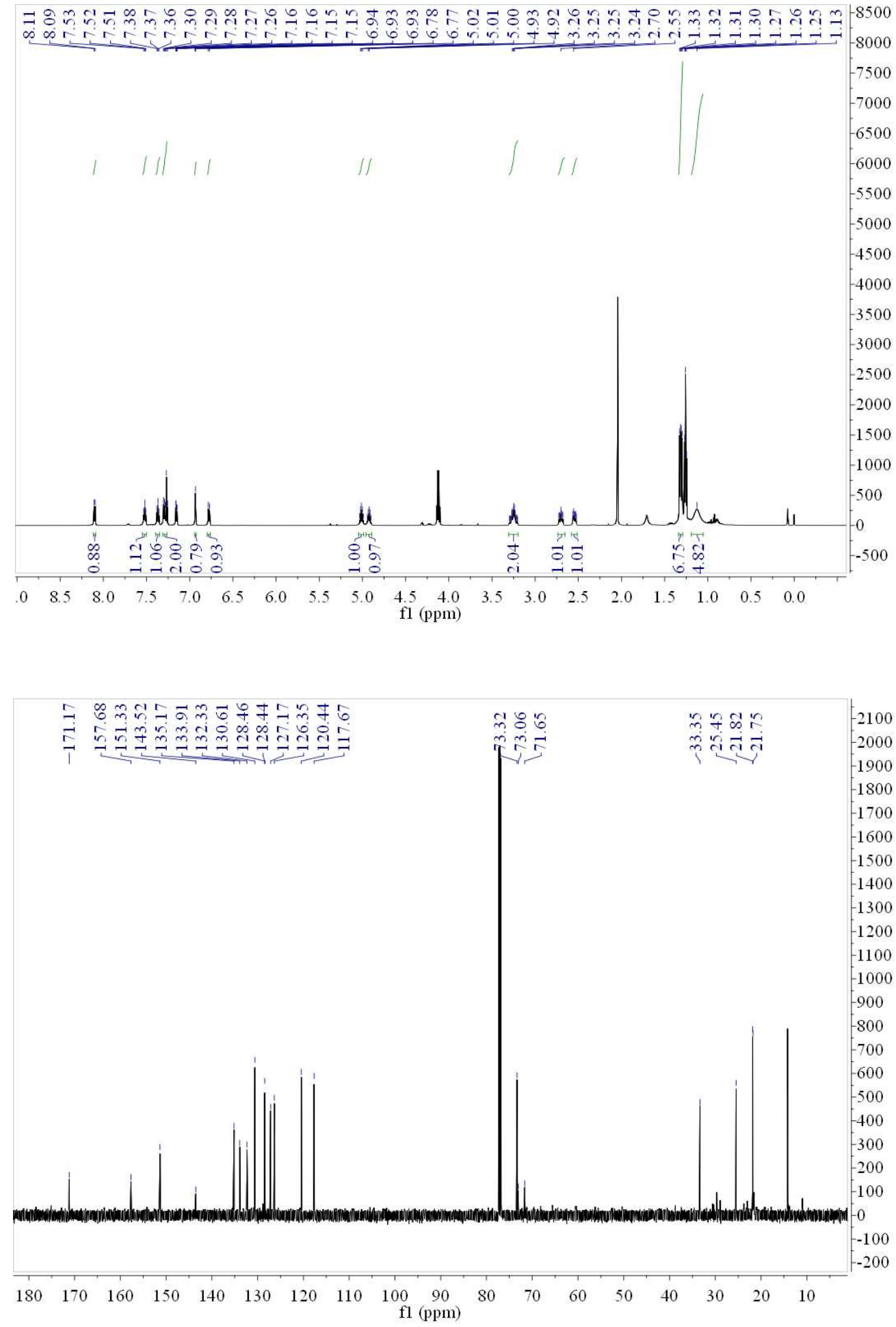
$4 i a$
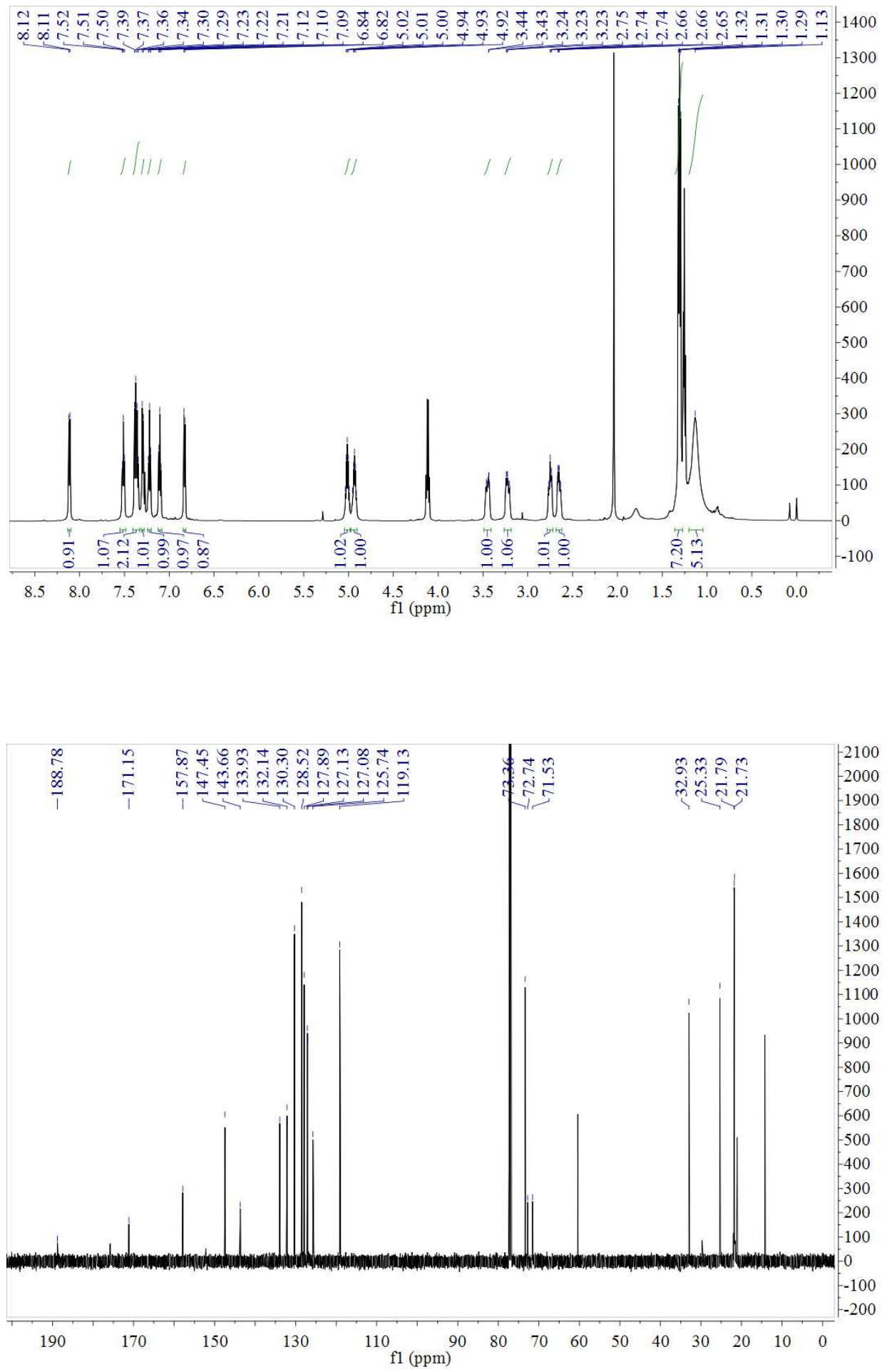
$4 j a$
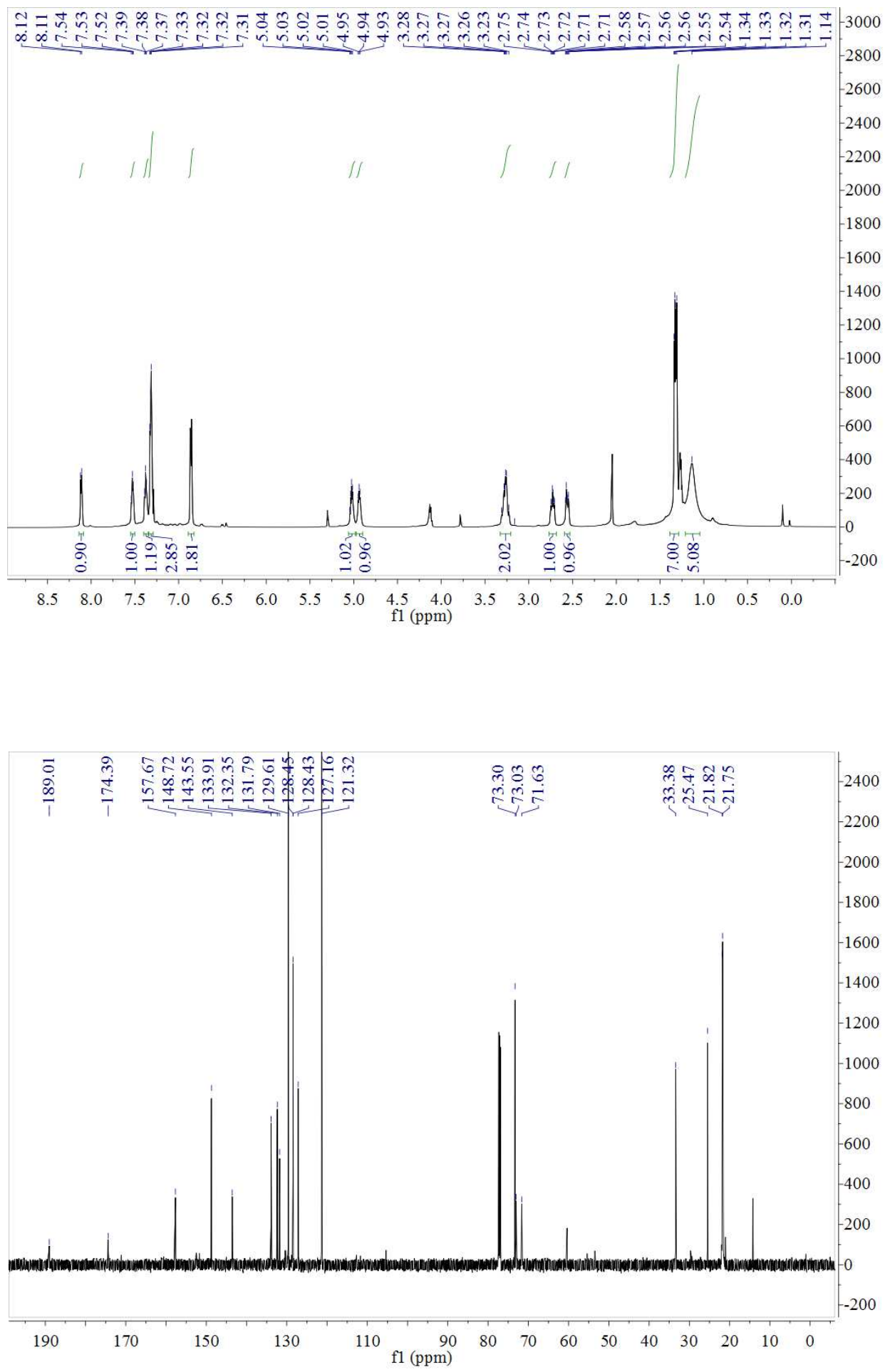
$4 \mathrm{ka}$
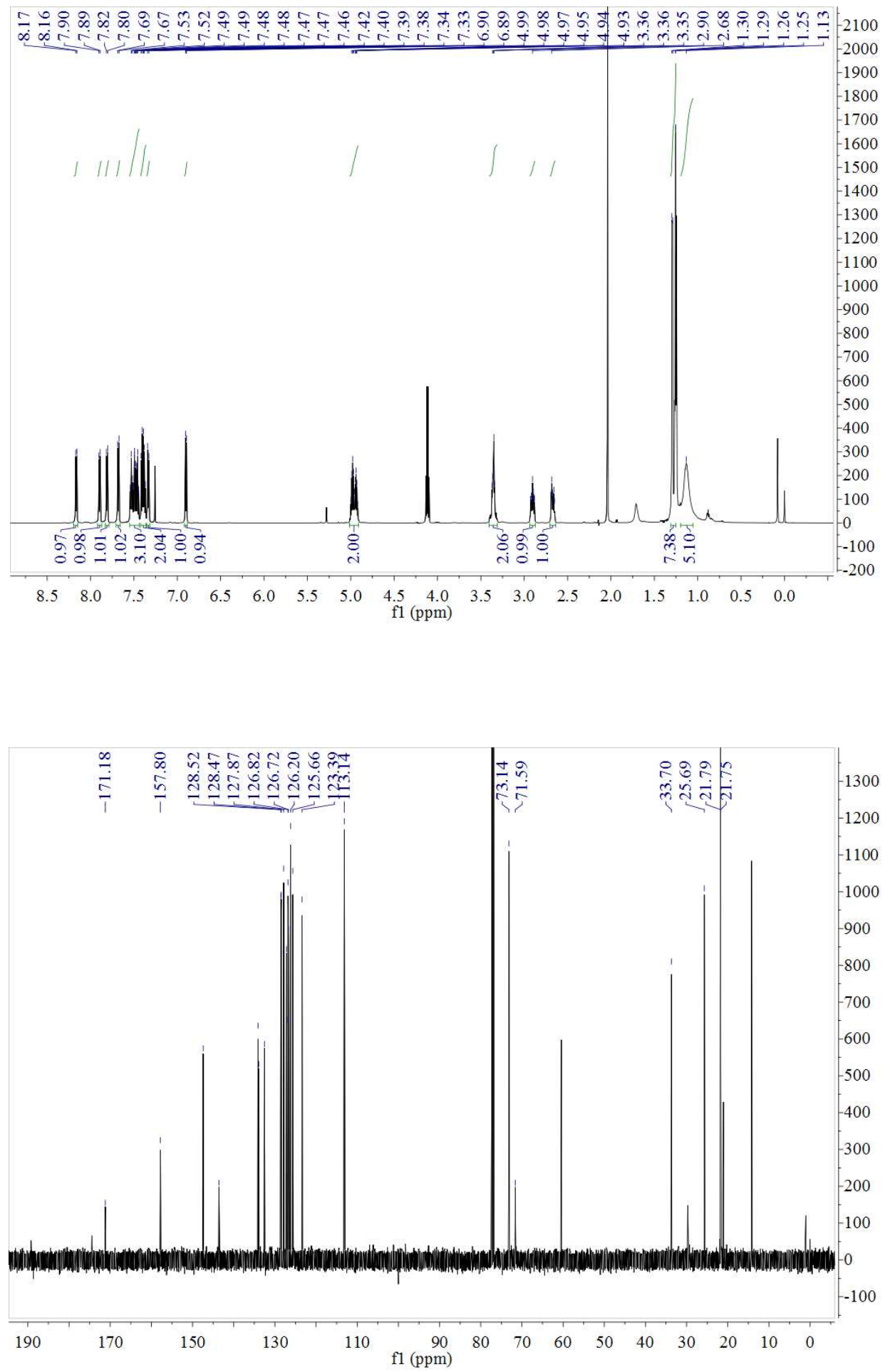
$4 \mathrm{eb}$
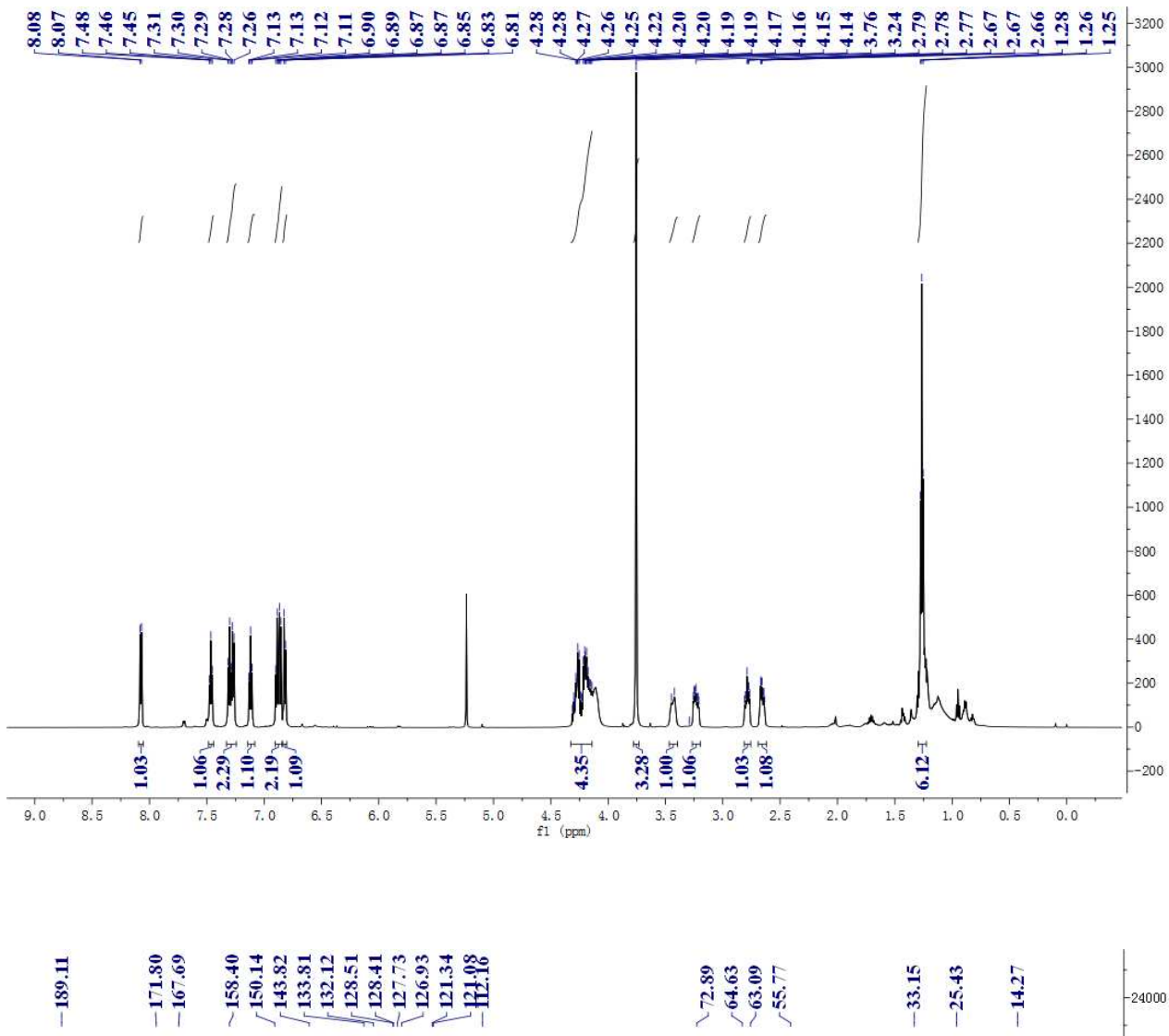

के 305



$-24000$

$-22000$

20000

$-18000$

$-16000$

$-14000$

$-12000$

$-10000$

8000

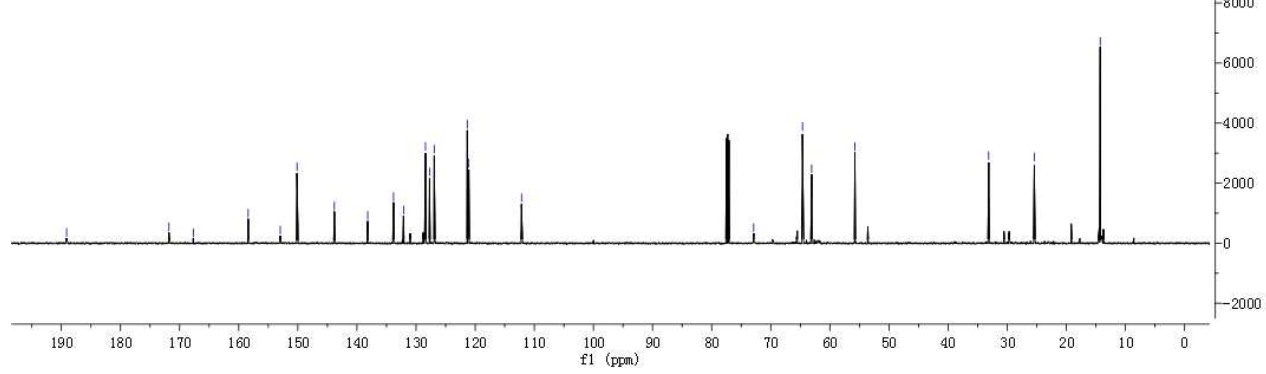



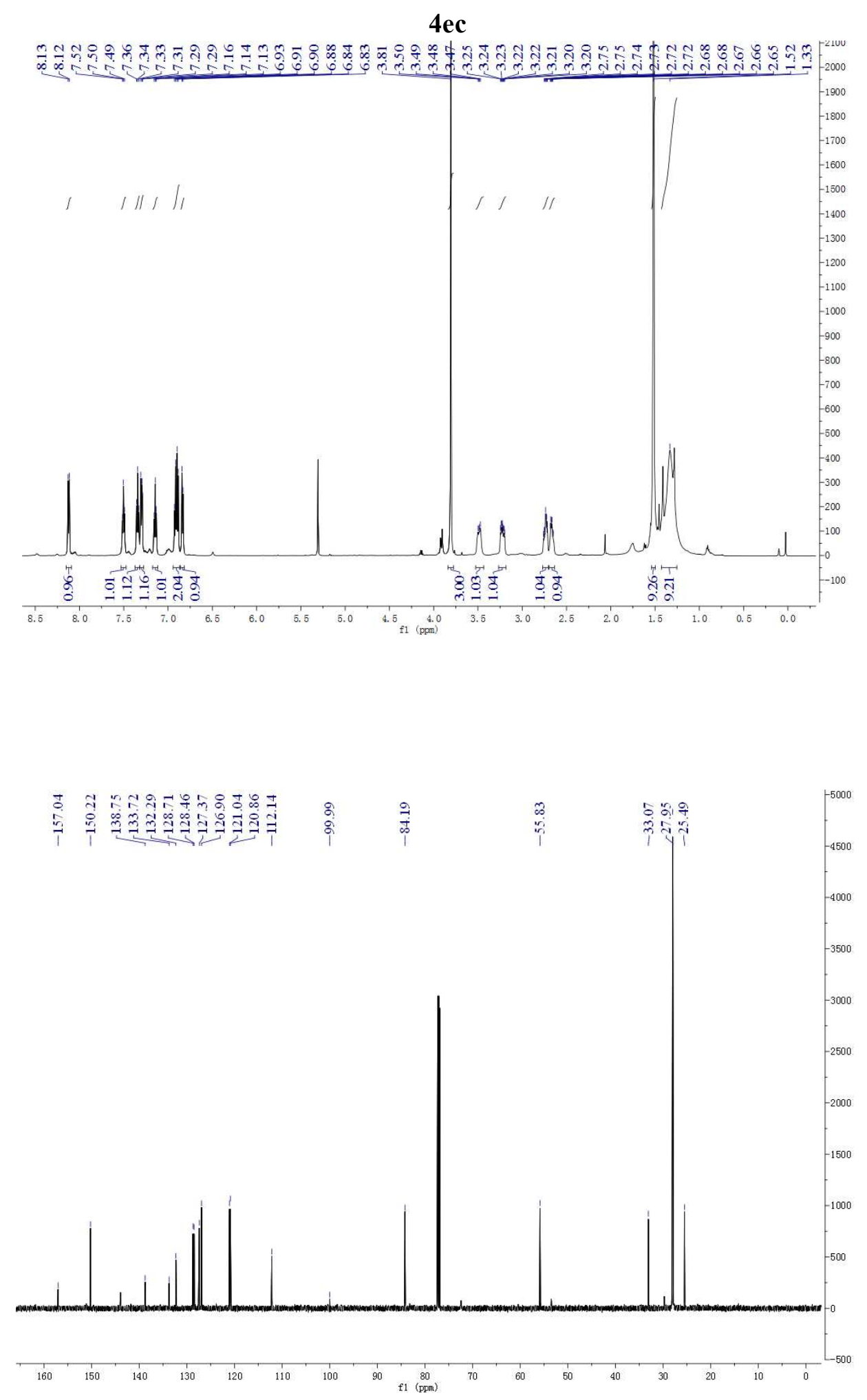

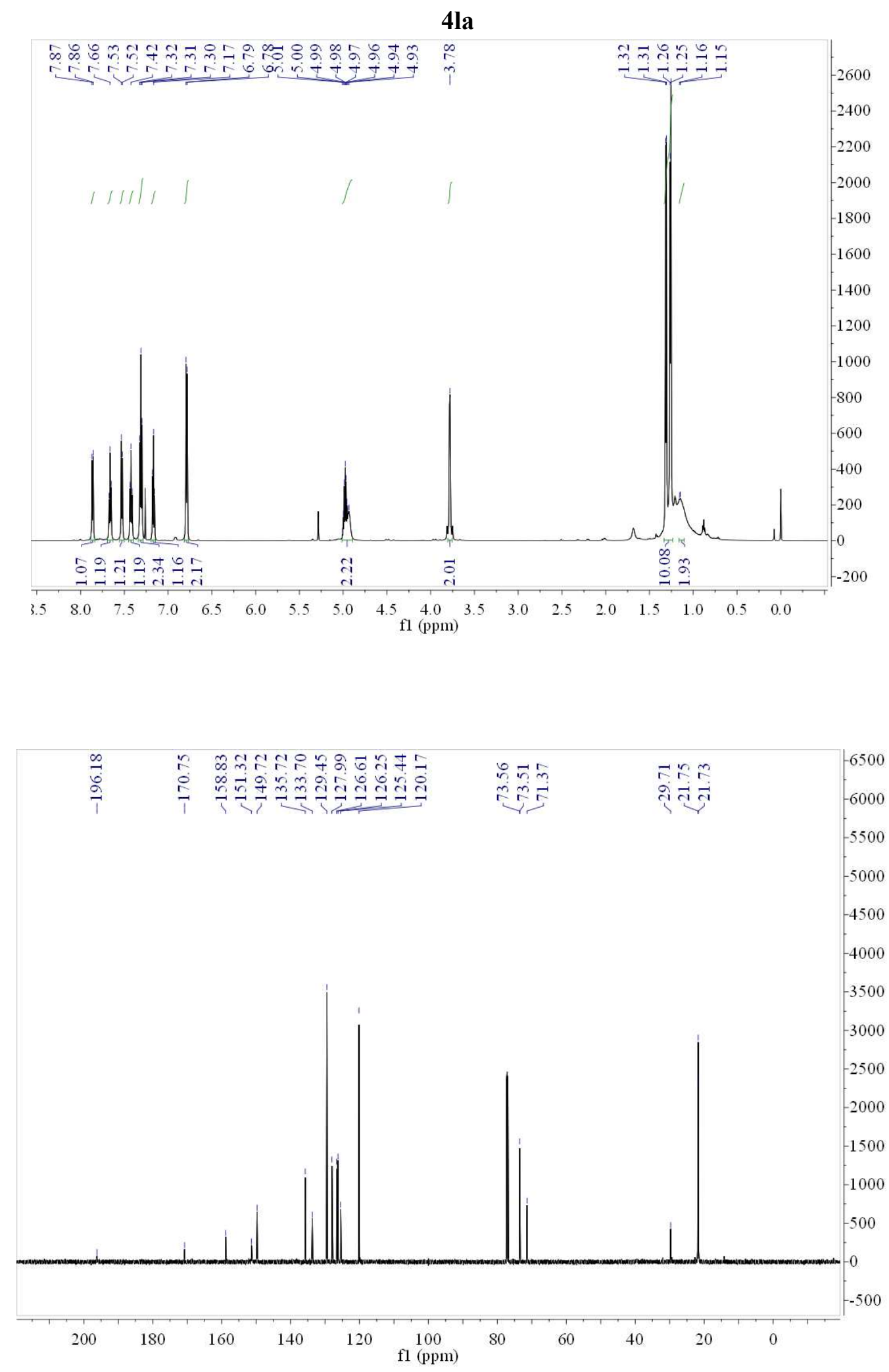
$4 \mathrm{ma}$

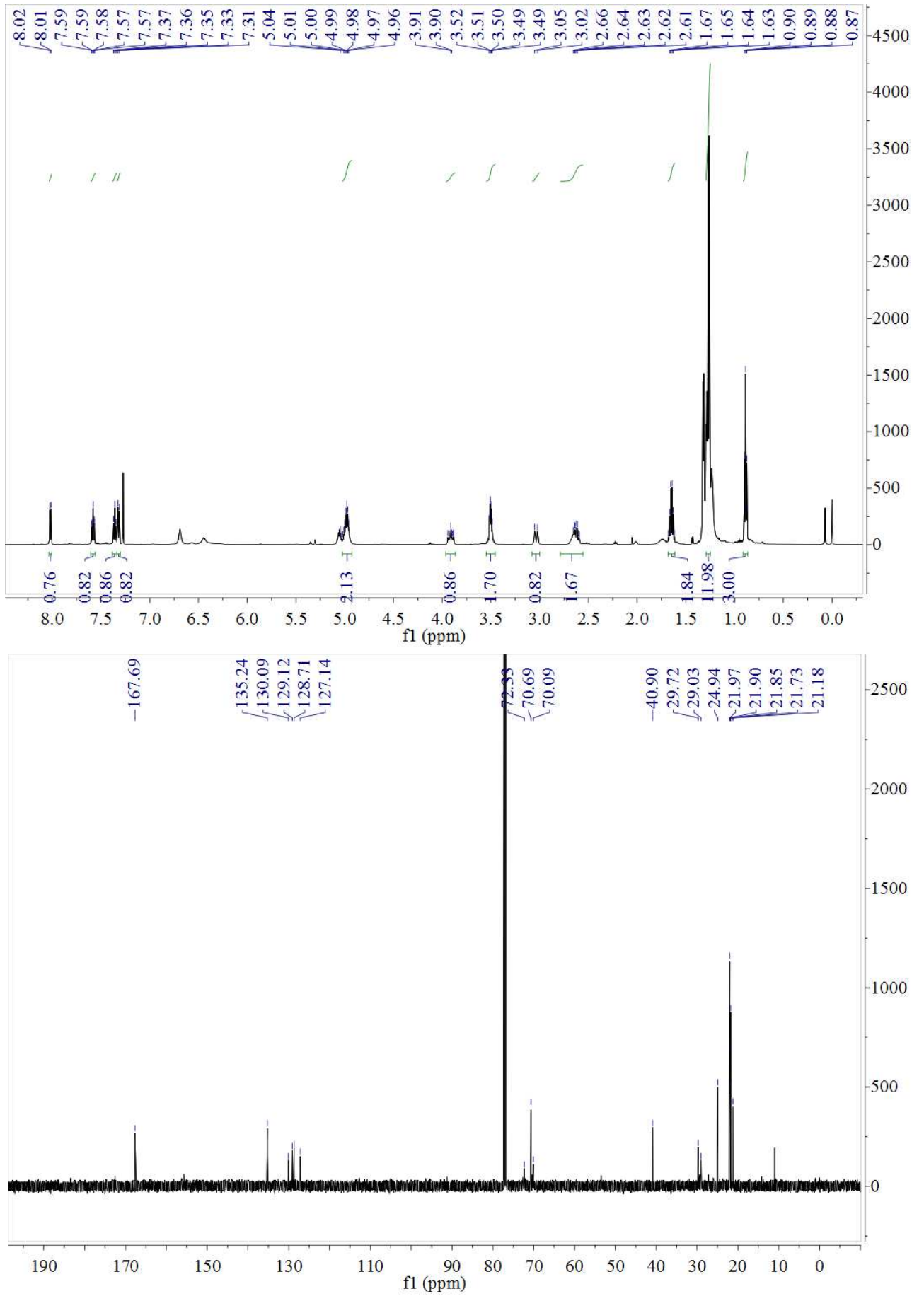




\section{Iaa}
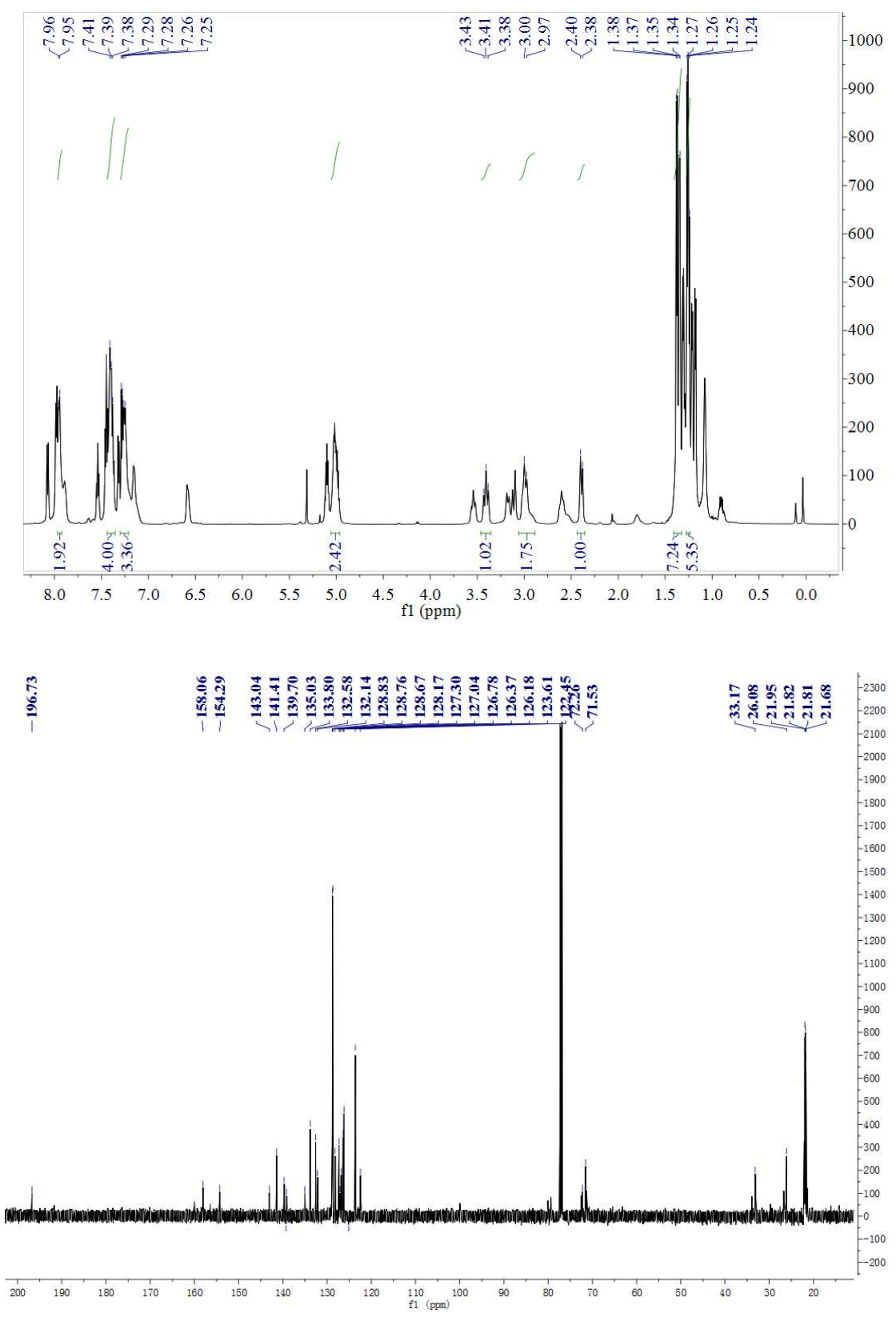


\section{HPLC spectra}
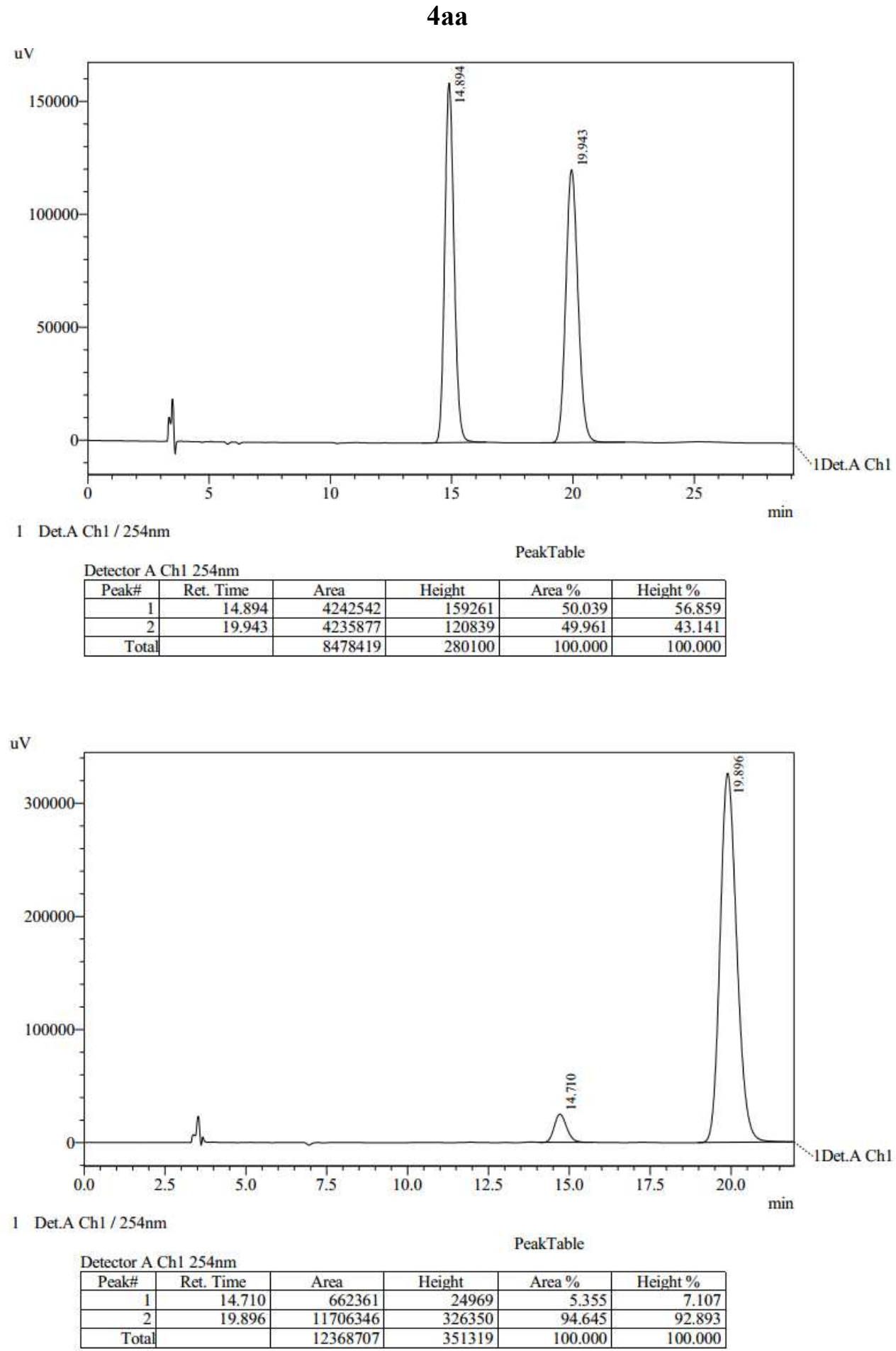
$4 a b$

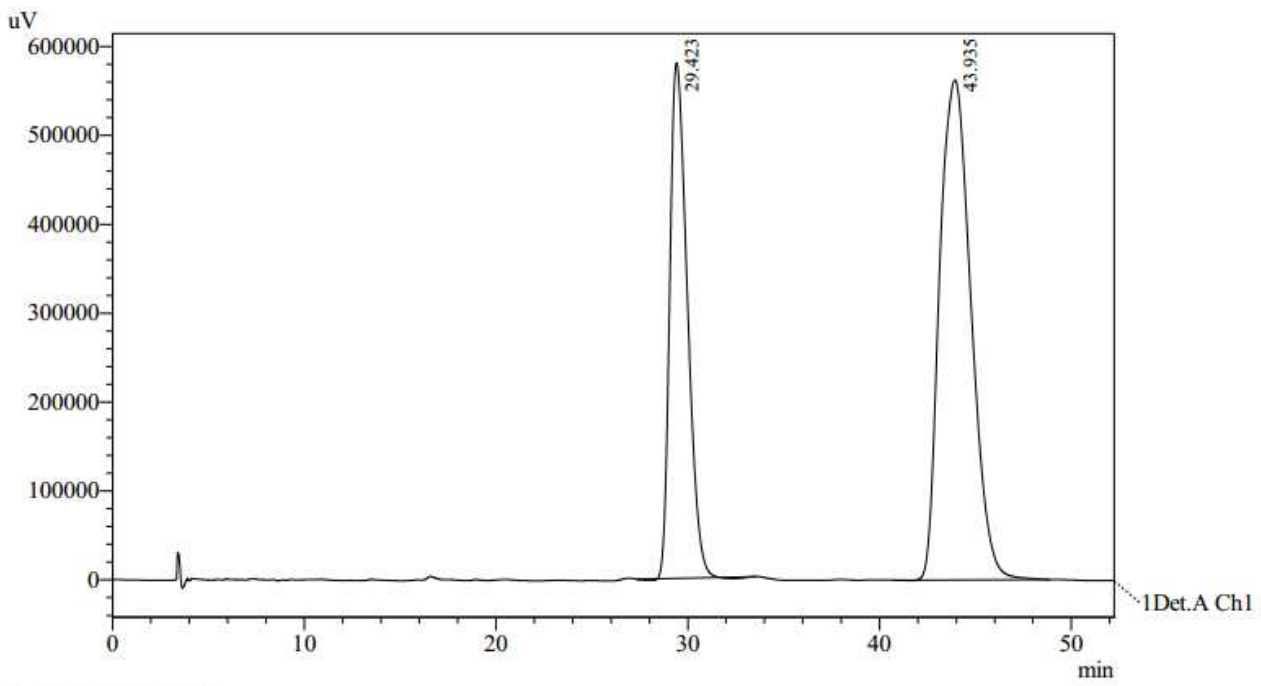

1 Det.A Chl / 254nm

Detector A Ch1 $254 \mathrm{~nm}$
\begin{tabular}{|r|r|r|r|r|r|}
\hline Peak\# & Ret. Time & \multicolumn{1}{c|}{ Area } & Height & \multicolumn{1}{c|}{ Area $\%$} & \multicolumn{1}{c|}{ Height $\%$} \\
\hline 1 & 29.423 & 36630013 & 579984 & 36.427 & 50.760 \\
\hline 2 & 43.935 & 63928230 & 562607 & 63.573 & 49.240 \\
\hline Total & & 100558243 & 1142591 & 100.000 & 100.000 \\
\hline
\end{tabular}

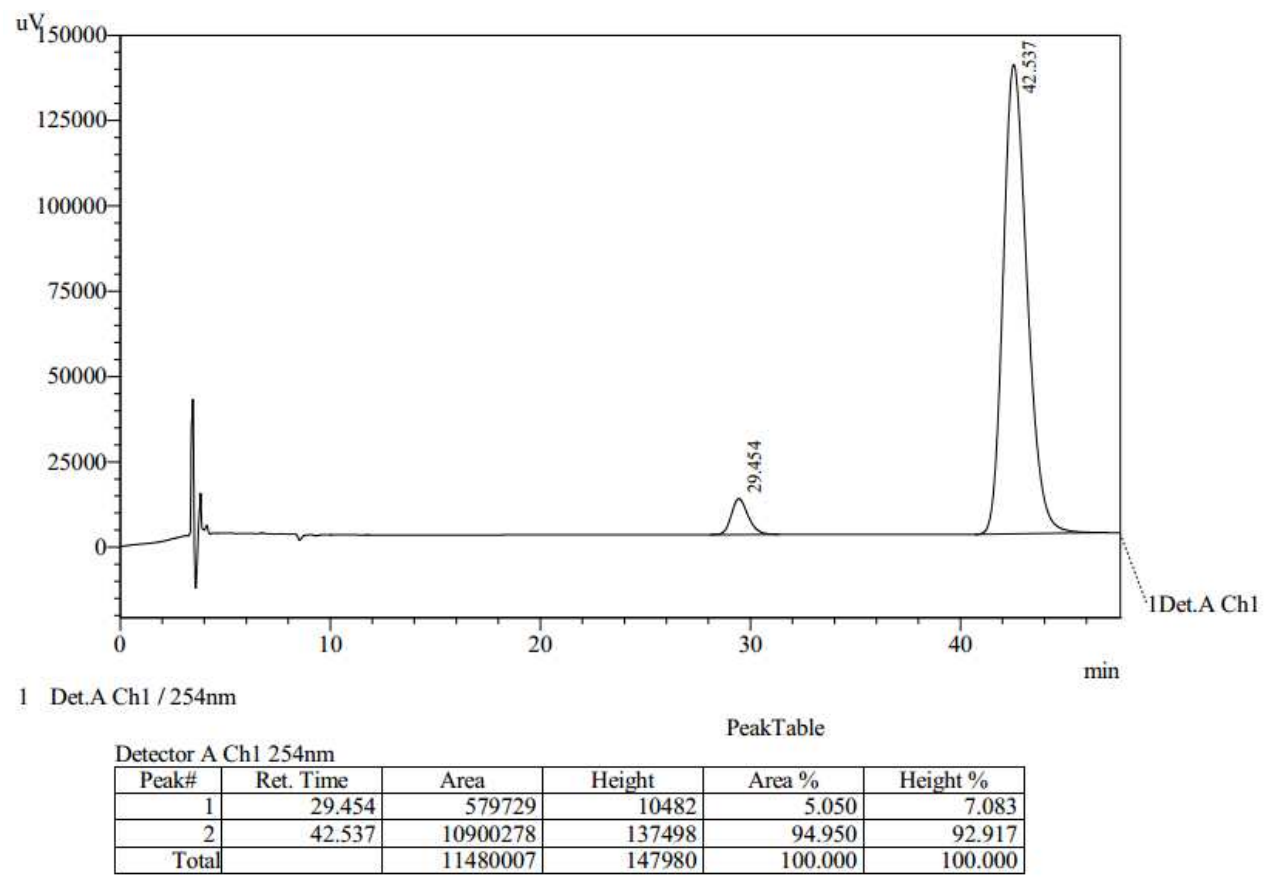


$4 a c$

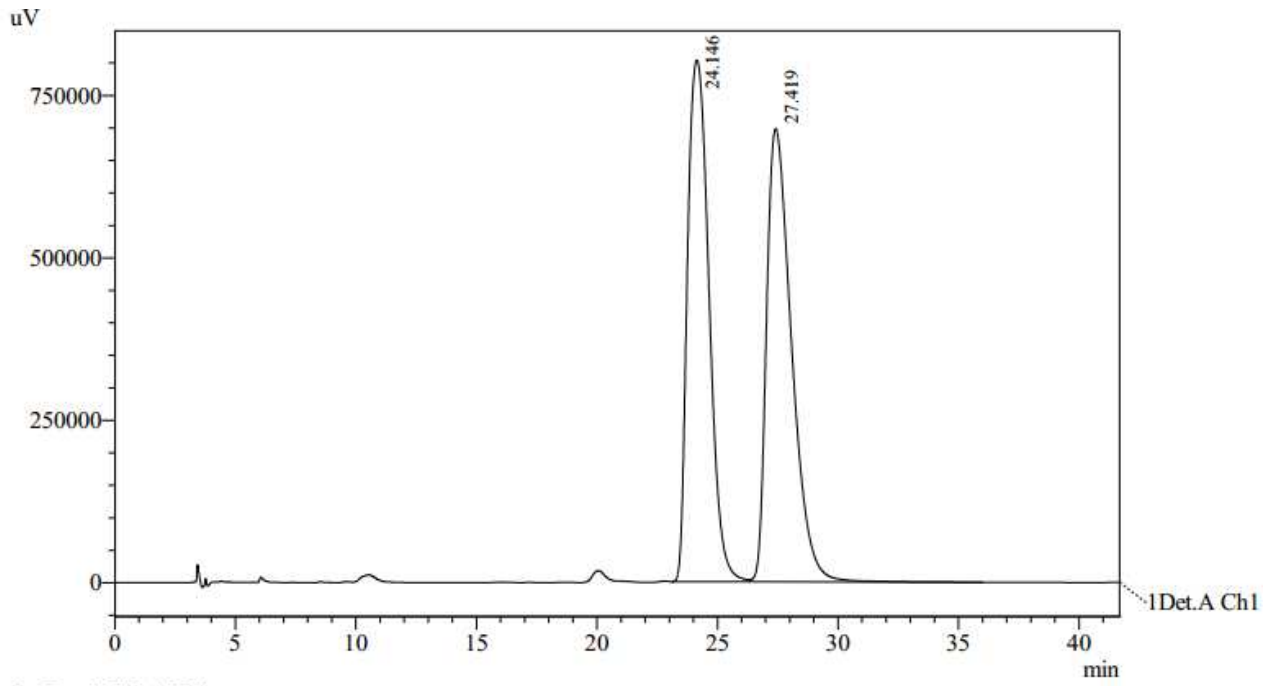

1 Det.A Ch1 / 254nm

Detector A ChI $254 \mathrm{~nm}$
\begin{tabular}{|r|r|r|r|r|r|}
\hline Peak\# & Ret. Time & \multicolumn{1}{|c|}{ Area } & Height & \multicolumn{1}{|c|}{ Area $\%$} & \multicolumn{1}{c|}{ Height $\%$} \\
\hline 1 & 24.146 & 49825238 & 802717 & 49.727 & 53.494 \\
\hline 2 & 27.419 & 50371478 & 697856 & 50.273 & 46.506 \\
\hline Total & & 100196716 & 1500573 & 100.000 & 100.000 \\
\hline
\end{tabular}

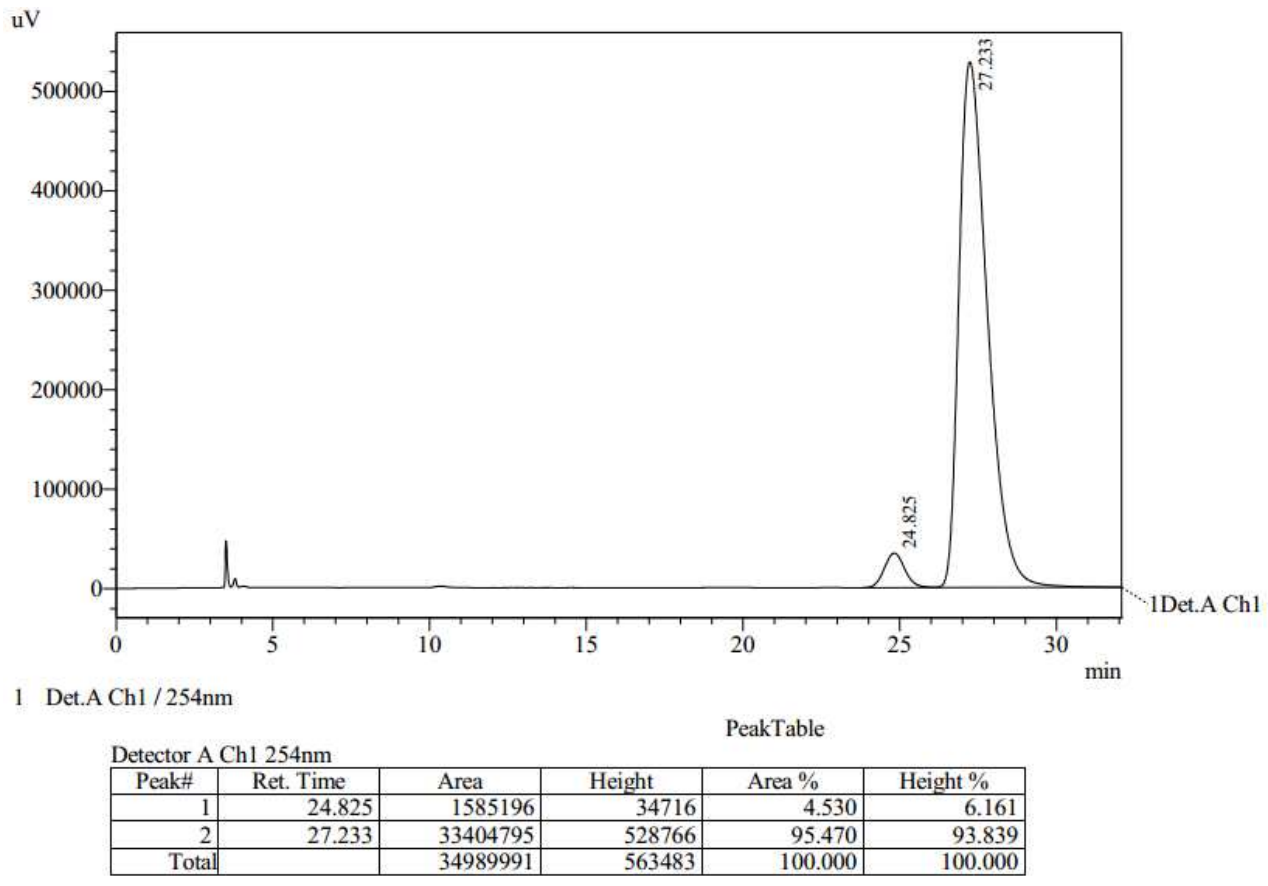


$4 \mathrm{ba}$
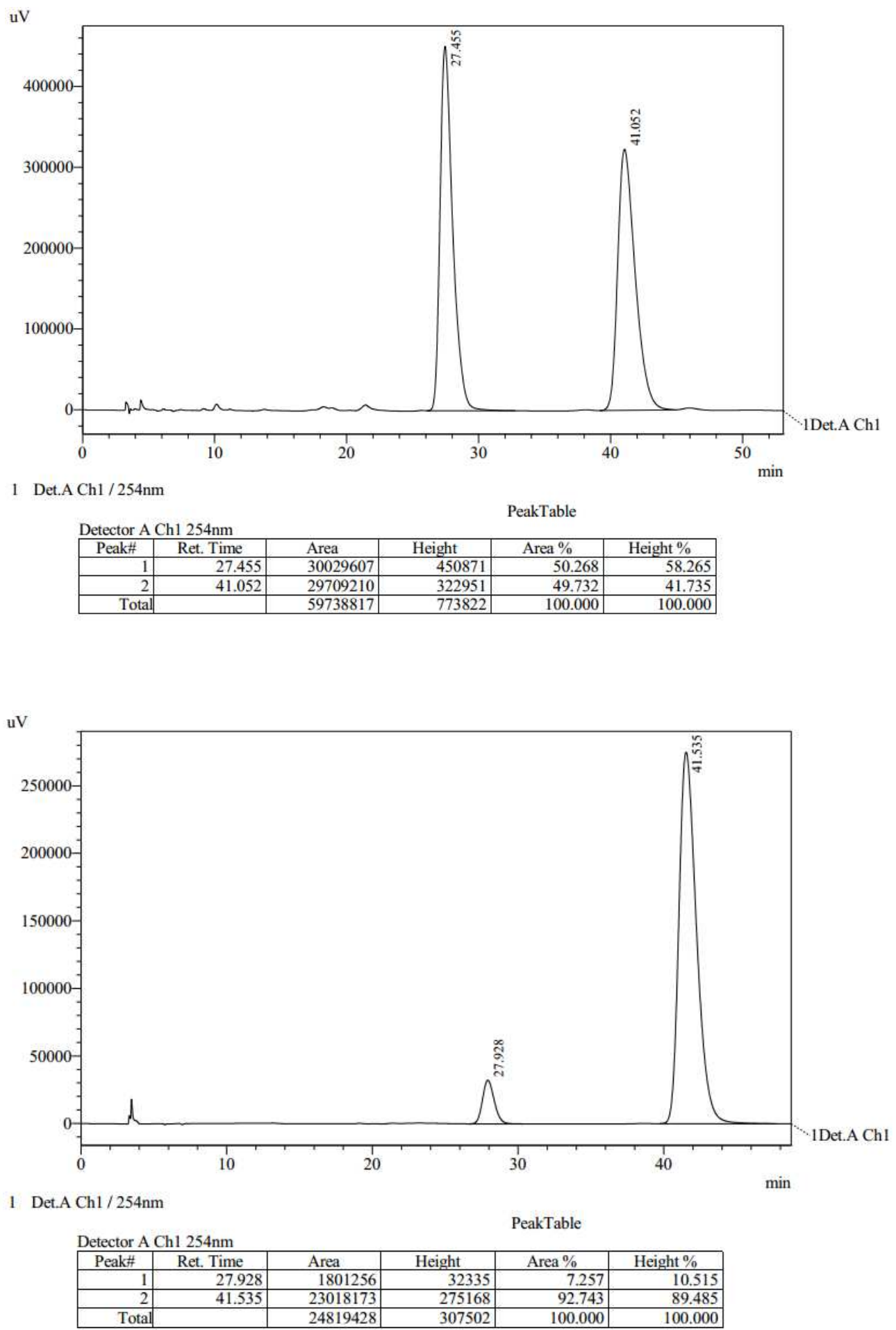
$4 c a$

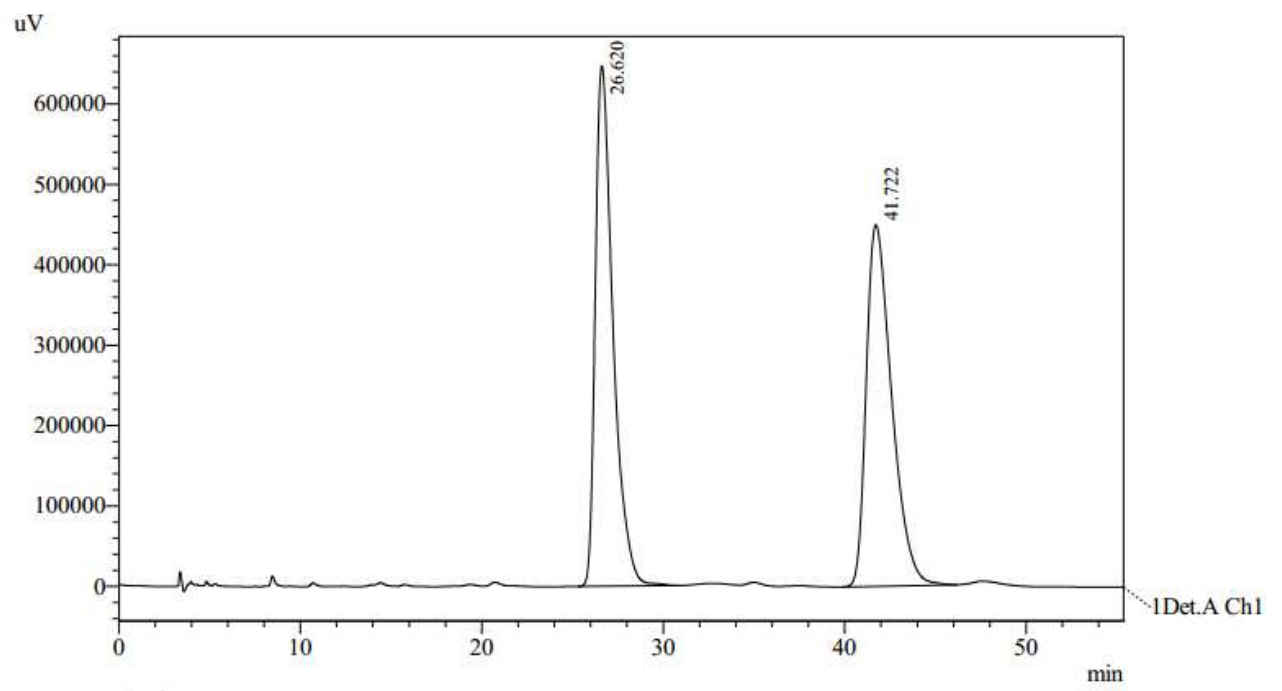

1 Det.A Chl $/ 254 \mathrm{~nm}$

Detector A Ch1 254nm
\begin{tabular}{|r|r|r|r|r|r|}
\hline \multicolumn{1}{|c|}{ Peak\# } & Ret. Time & \multicolumn{1}{|c|}{ Area } & Height & \multicolumn{1}{c|}{ Area \% } & \multicolumn{1}{c|}{ Height $\%$} \\
\hline 1 & 26.620 & 43995744 & 647611 & 50.135 & 59.024 \\
\hline 2 & 41.722 & 43759431 & 449583 & 49.865 & 40.976 \\
\hline Total & & 87755174 & 1097194 & 100.000 & 100.000 \\
\hline
\end{tabular}

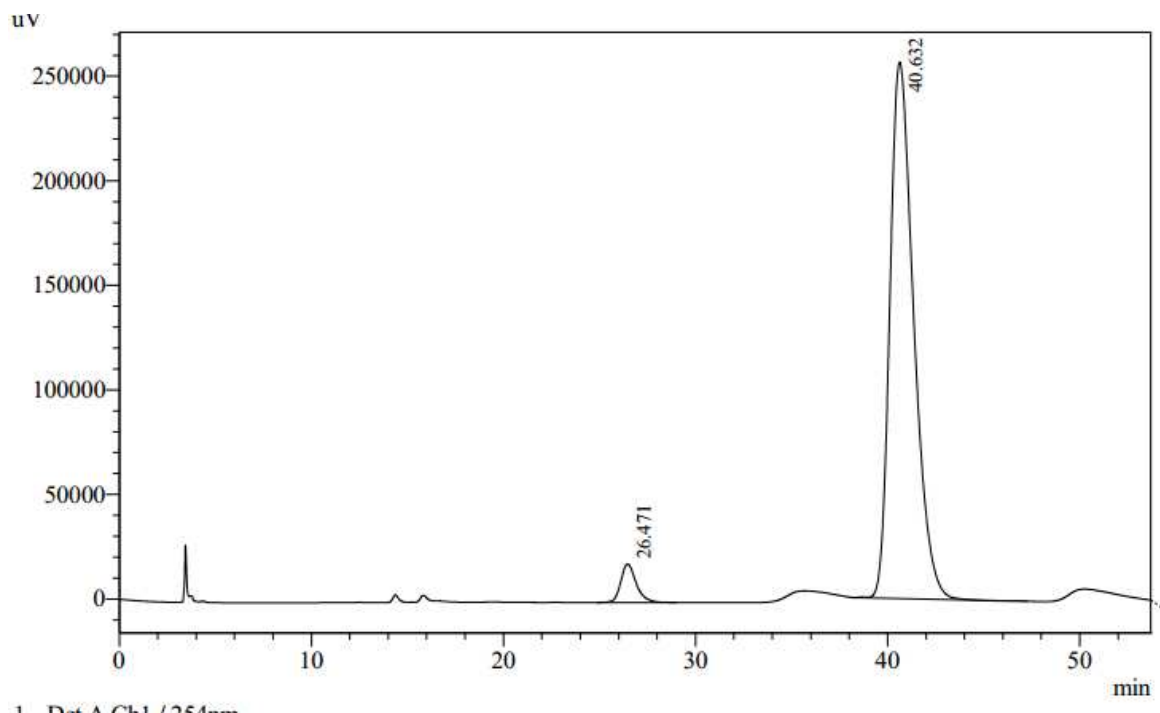

1 Det.A Ch1 / 254nm

Detector A Ch1 254nm
\begin{tabular}{|r|r|r|r|r|r|}
\hline Peak\# & Ret. Time & \multicolumn{1}{c|}{ Area } & Height & Area $\%$ & Height $\%$ \\
\hline 1 & 26.471 & 1030777 & 18382 & 4.464 & 6.688 \\
\hline 2 & 40.632 & 22061330 & 256465 & 95.536 & 93.312 \\
\hline Total & & 23092108 & 274847 & 100.000 & 100.000 \\
\hline
\end{tabular}


4da

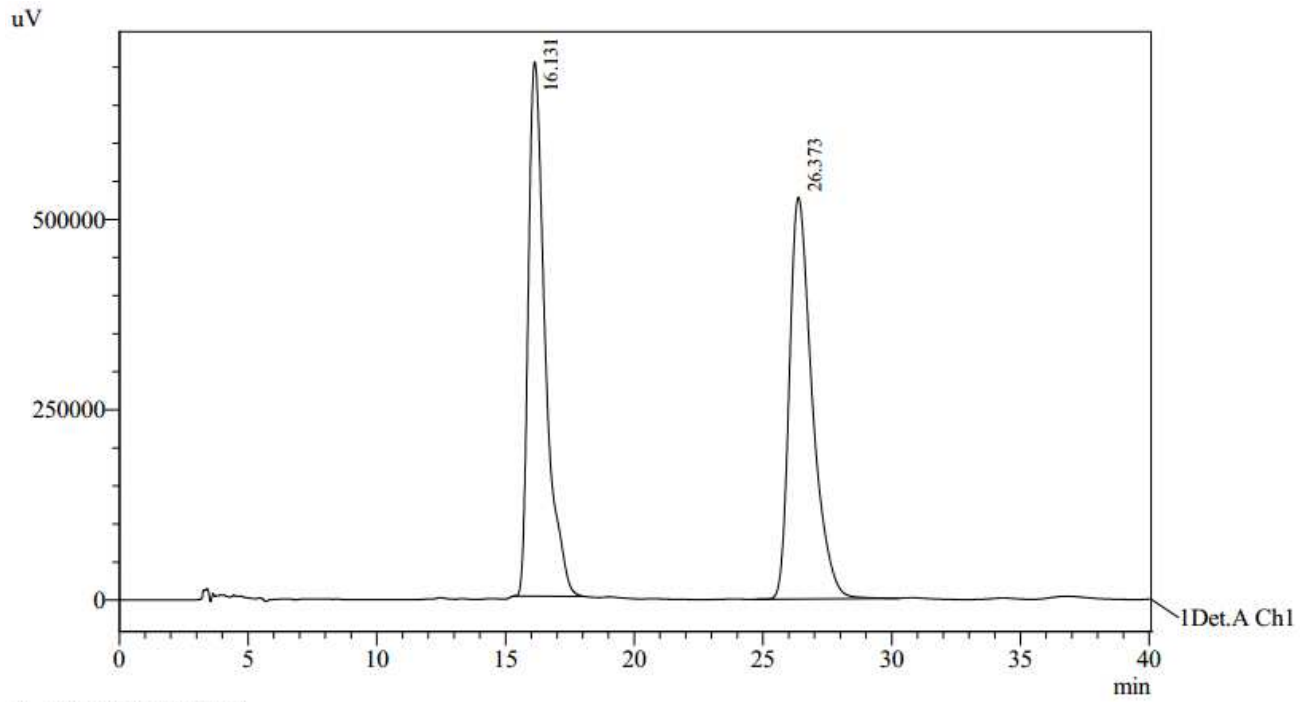

1 Det.A Chl / $254 \mathrm{~nm}$

Detector A Ch1 $254 \mathrm{~nm}$
\begin{tabular}{|r|r|l|r|r|r|}
\hline Peak\# & Ret. Time & \multicolumn{1}{|c|}{ Area } & \multicolumn{1}{c|}{ Height } & Area $\%$ & Height $\%$ \\
\hline 1 & 16.131 & 32040235 & 701760 & 49.632 & 57.072 \\
\hline 2 & 26.373 & 32515083 & 527842 & 50.368 & 42.928 \\
\hline Total & & 64555317 & 1229602 & 100.000 & 100.000 \\
\hline
\end{tabular}

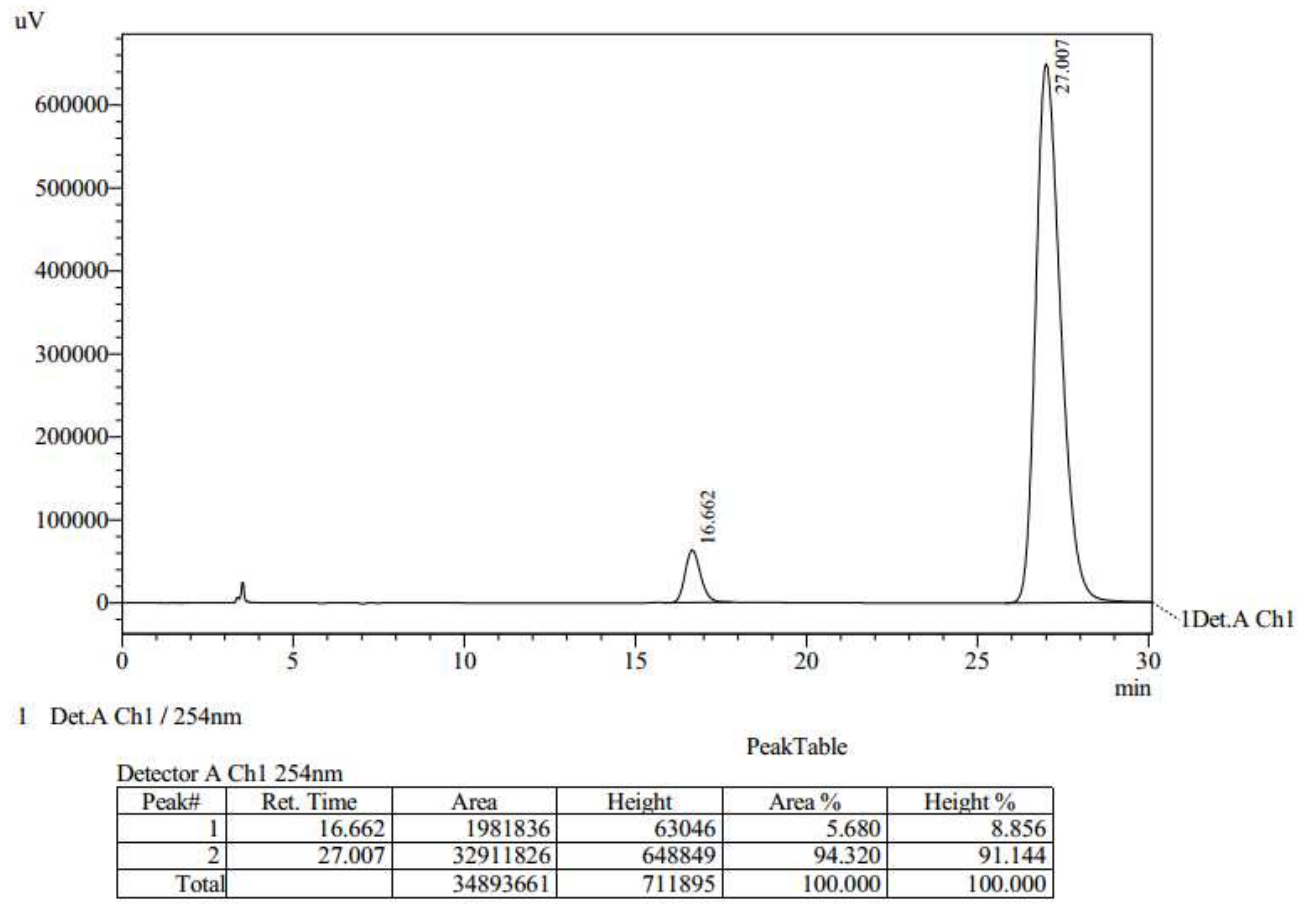


4ea
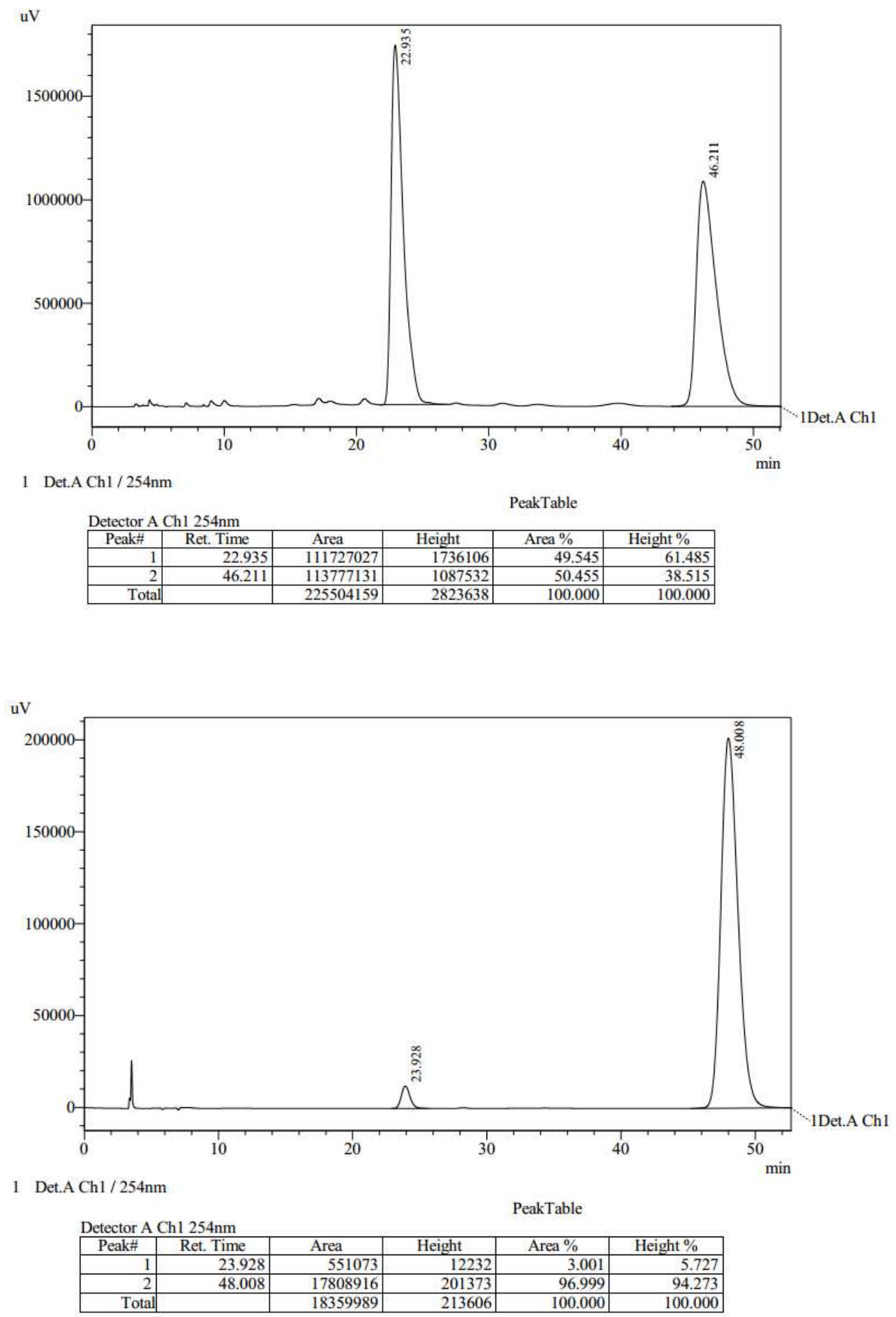
4fa
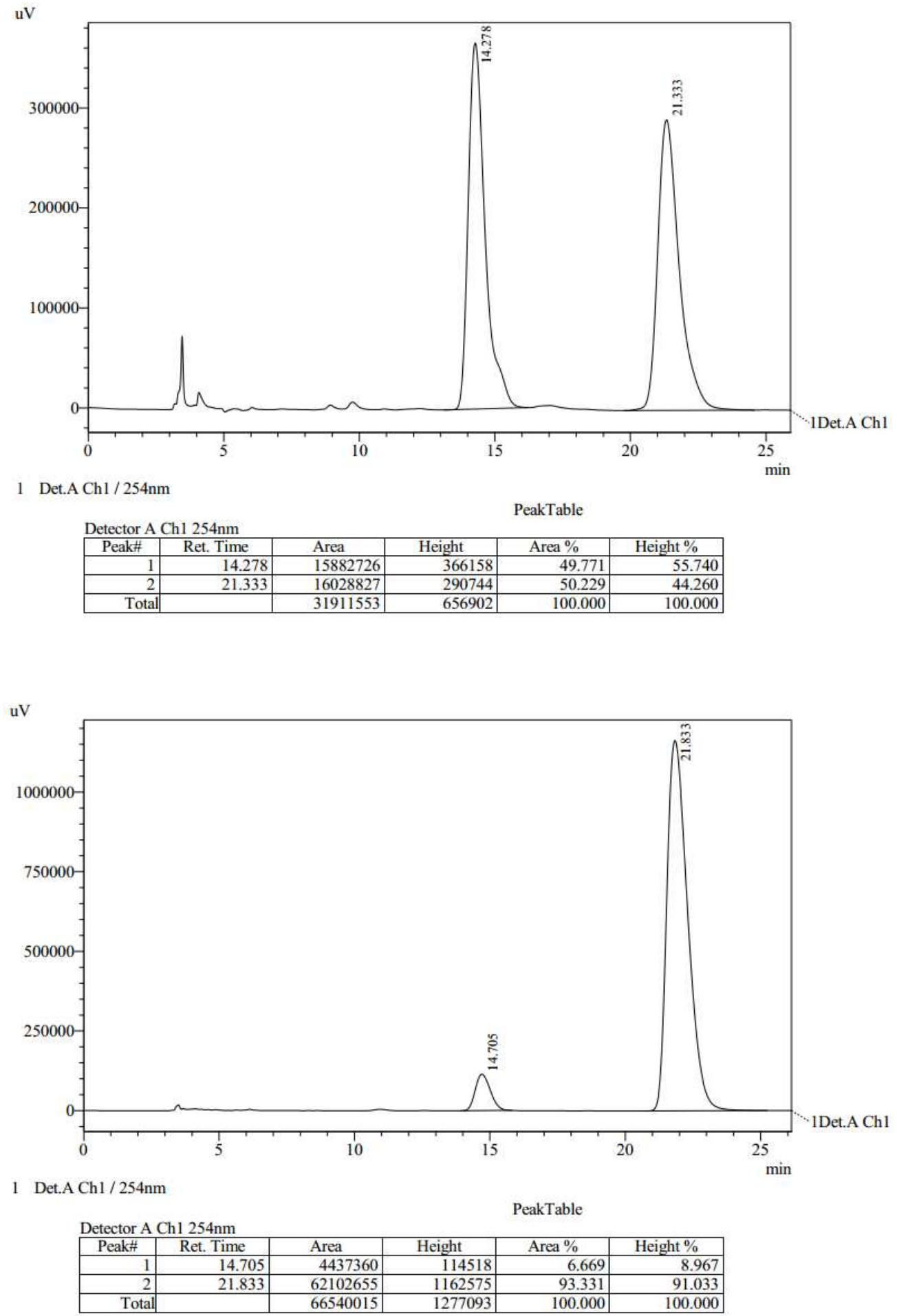
4ga
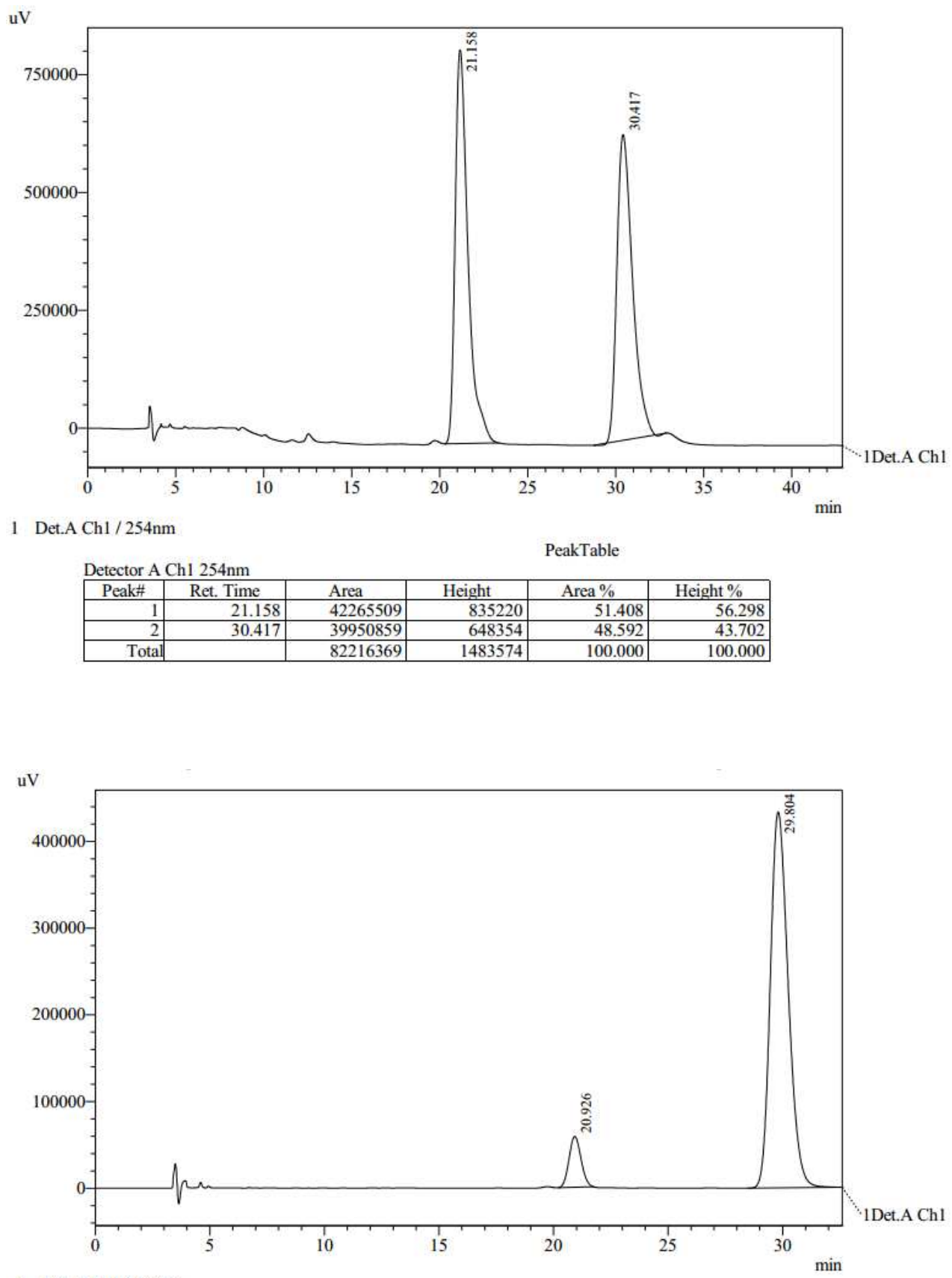

1 Det.A Ch1 $/ 254 \mathrm{~nm}$

Detector A Ch1 $254 \mathrm{~nm}$
\begin{tabular}{|r|r|r|r|r|r|}
\hline Peak\# & Ret. Time & \multicolumn{1}{|c|}{ Area } & Height & Area $\%$ & Height $\%$ \\
\hline 1 & 20.926 & 2131216 & 58647 & 8.314 & 11.912 \\
\hline 2 & 29.804 & 23501921 & 433707 & 91.686 & 88.088 \\
\hline Total & & 25633136 & 492354 & 100.000 & 100.000 \\
\hline
\end{tabular}


4ha

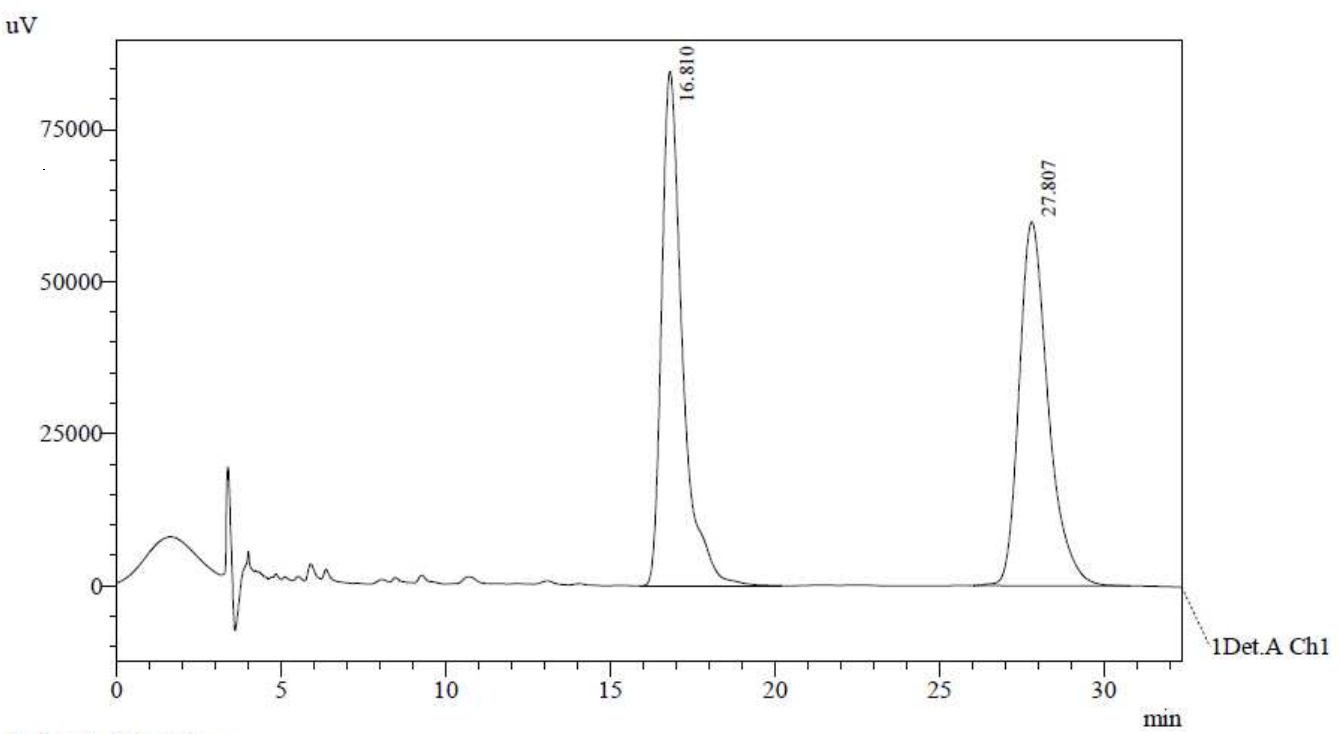

1 Det.A Ch1 / 254nm

Detector A Ch1 254nm
\begin{tabular}{|r|r|r|r|r|r|}
\hline \multicolumn{1}{|c|}{ Peak\# } & Ret. Time & \multicolumn{1}{|c|}{ Area } & Height & Area $\%$ & \multicolumn{1}{c|}{ Height $\%$} \\
\hline 1 & 16.810 & 3739441 & 84645 & 50.358 & 58.575 \\
\hline 2 & 27.807 & 3686219 & 59863 & 49.642 & 41.425 \\
\hline Total & & 7425659 & 144507 & 100.000 & 100.000 \\
\hline
\end{tabular}

uV

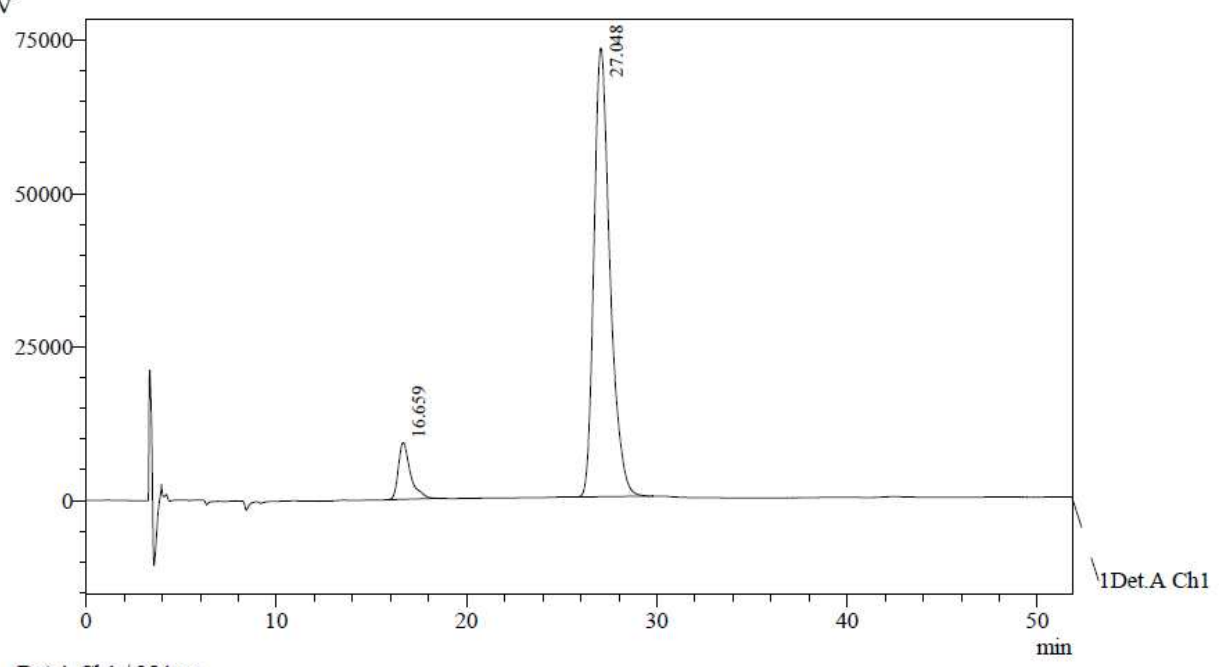

1 Det.A Ch1 $/ 254 \mathrm{~nm}$

Detector A Ch1 254nm
\begin{tabular}{|r|r|r|r|r|r|}
\hline \multicolumn{1}{|c|}{ Peak\# } & Ret. Time & \multicolumn{1}{|c|}{ Area } & Height & Area $\%$ & Height $\%$ \\
\hline 1 & 16.659 & 406165 & 9252 & 8.659 & 11.229 \\
\hline 2 & 27.048 & 4284636 & 73137 & 91.341 & 88.771 \\
\hline Total & & 4690801 & 82389 & 100.000 & 100.000 \\
\hline
\end{tabular}


4ia

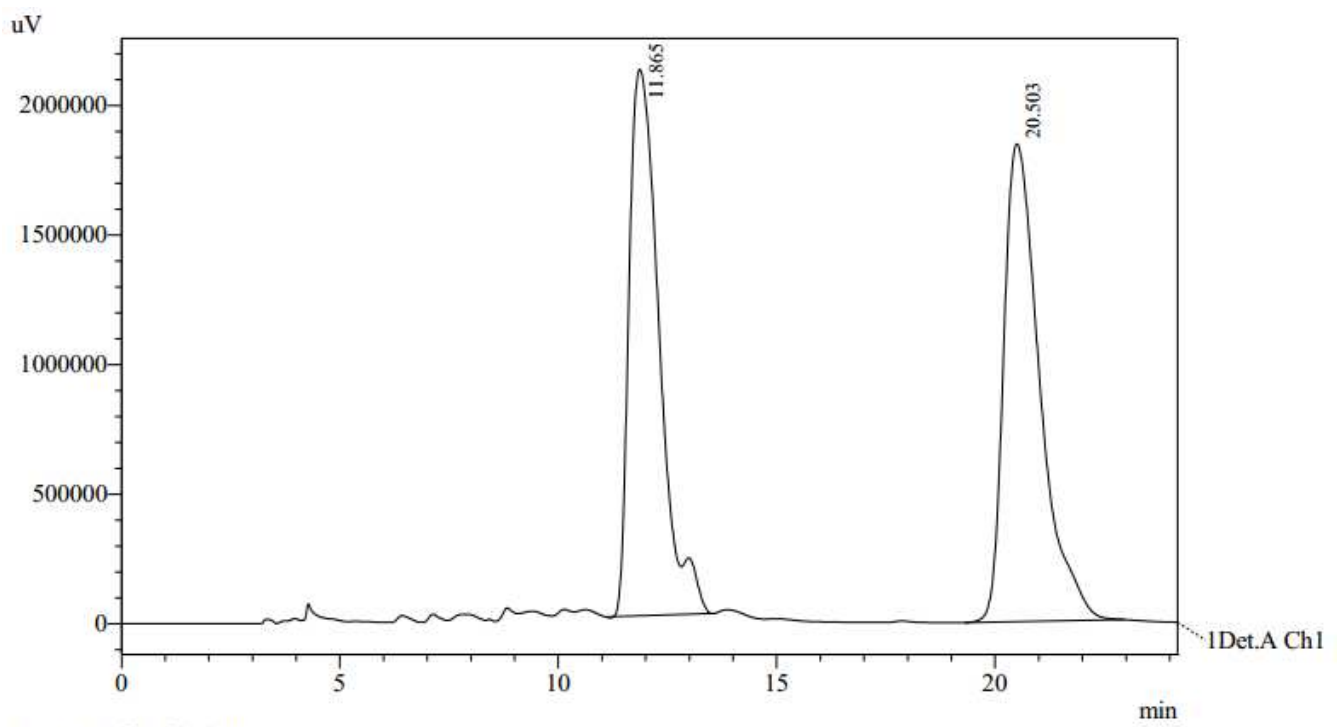

1 Det.A Chl / 254nm

Detector A Ch1 254nm
\begin{tabular}{|r|r|r|r|r|r|}
\hline Peak\# & Ret. Time & Area & Height & Area $\%$ & \multicolumn{1}{|c|}{ Height $\%$} \\
\hline 1 & 11.865 & 101061605 & 2109152 & 48.799 & 53.354 \\
\hline 2 & 20.503 & 106036269 & 1843953 & 51.201 & 46.646 \\
\hline Total & & 207097874 & 3953105 & 100.000 & 100.000 \\
\hline
\end{tabular}

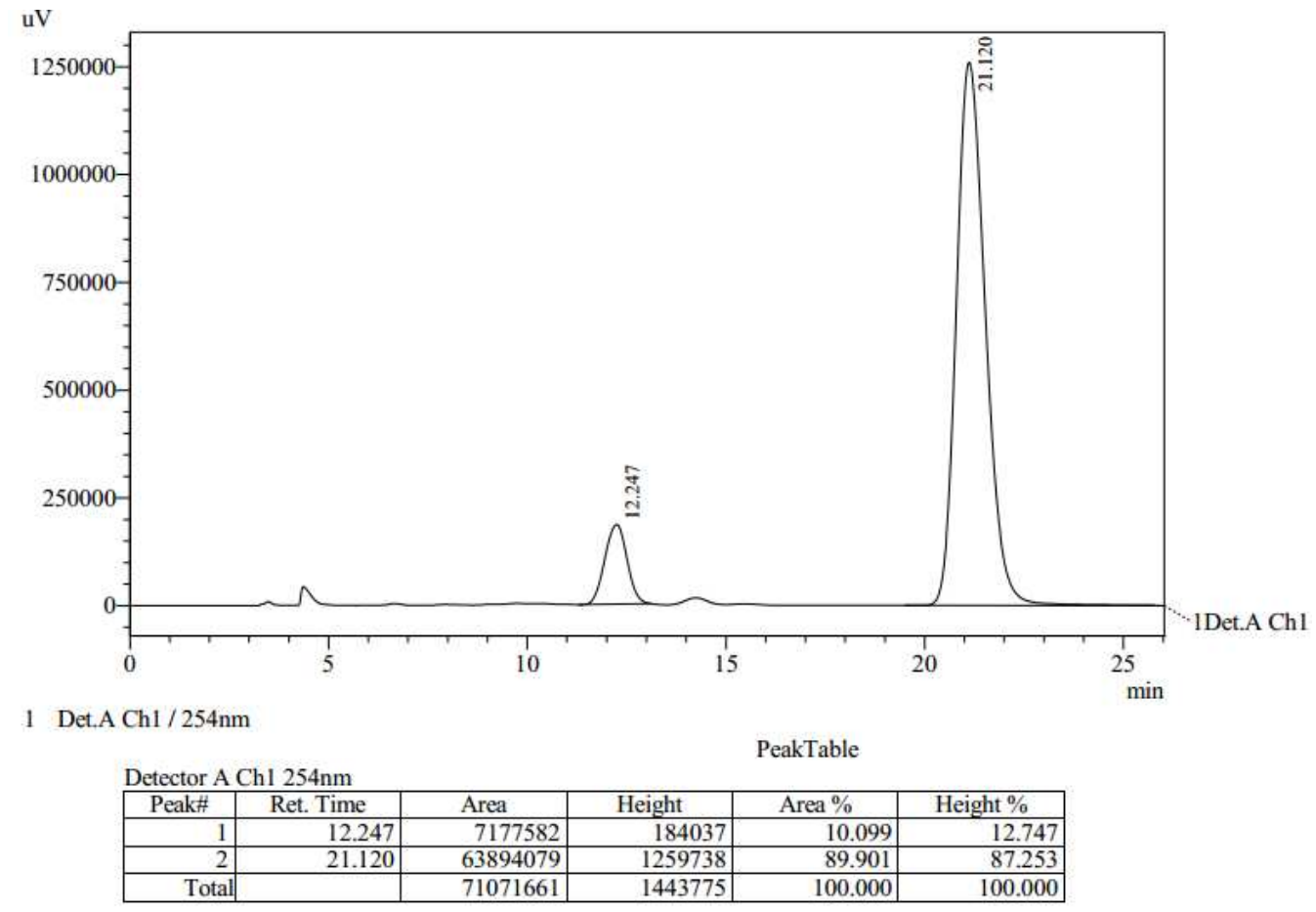



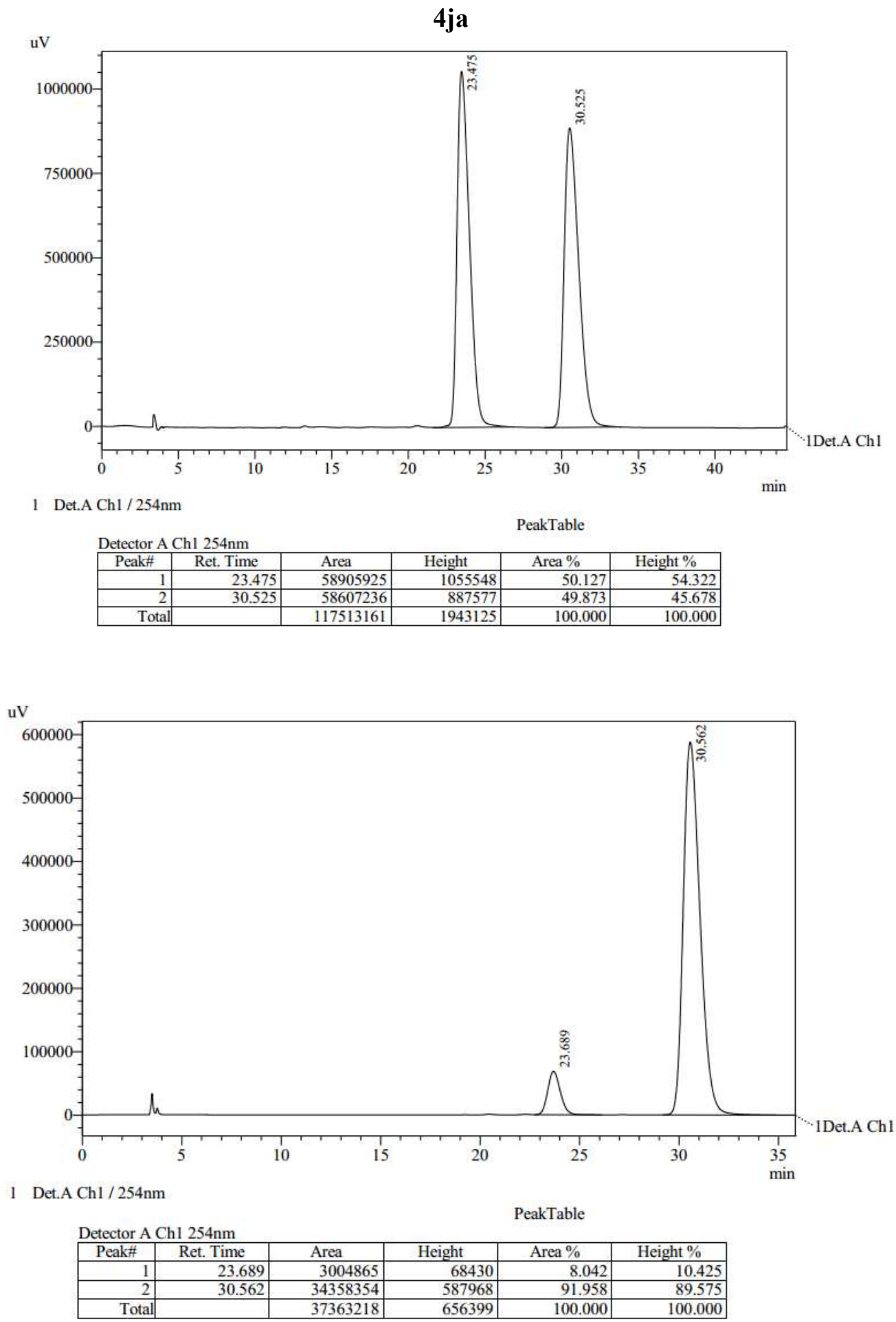
4ka
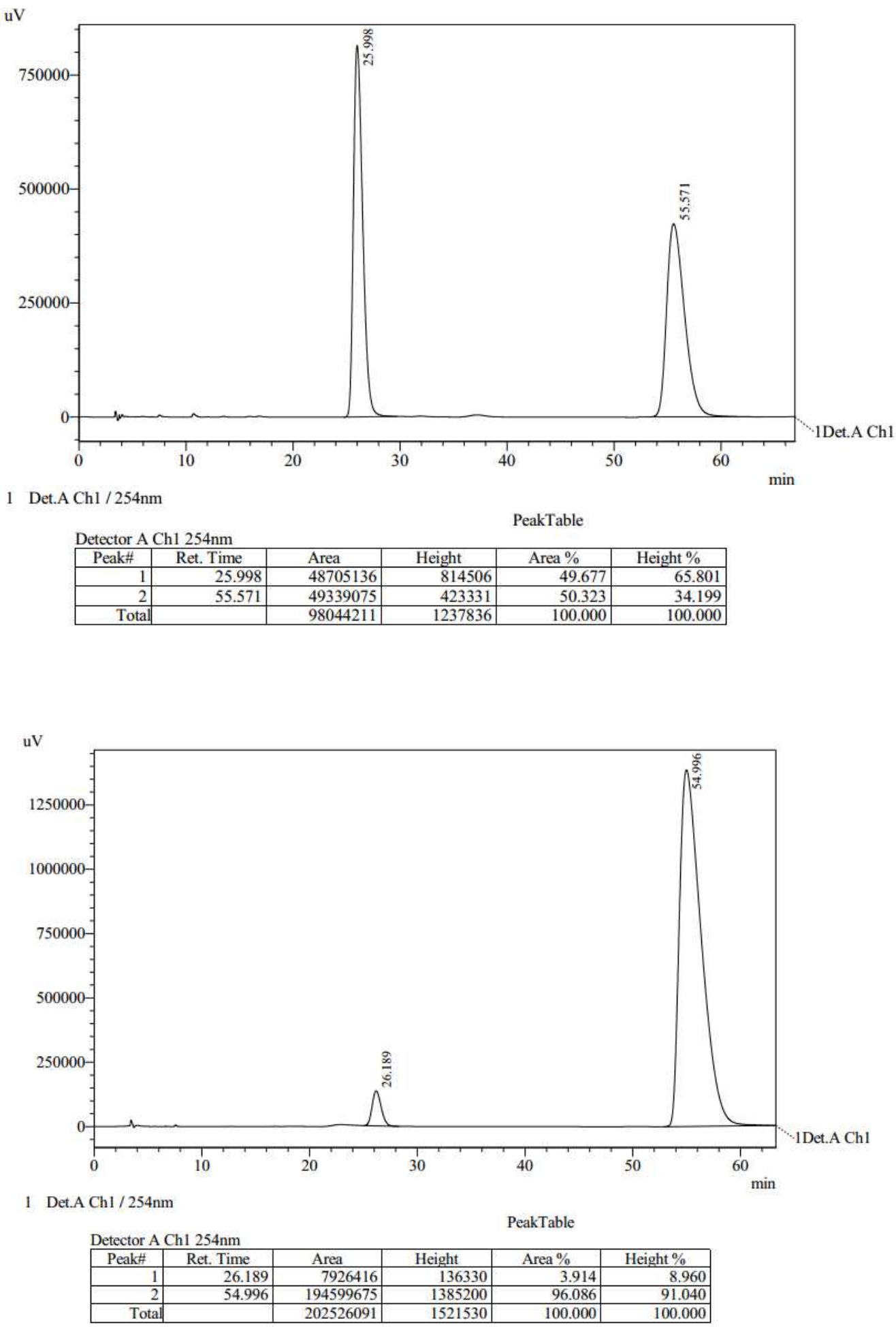
4eb
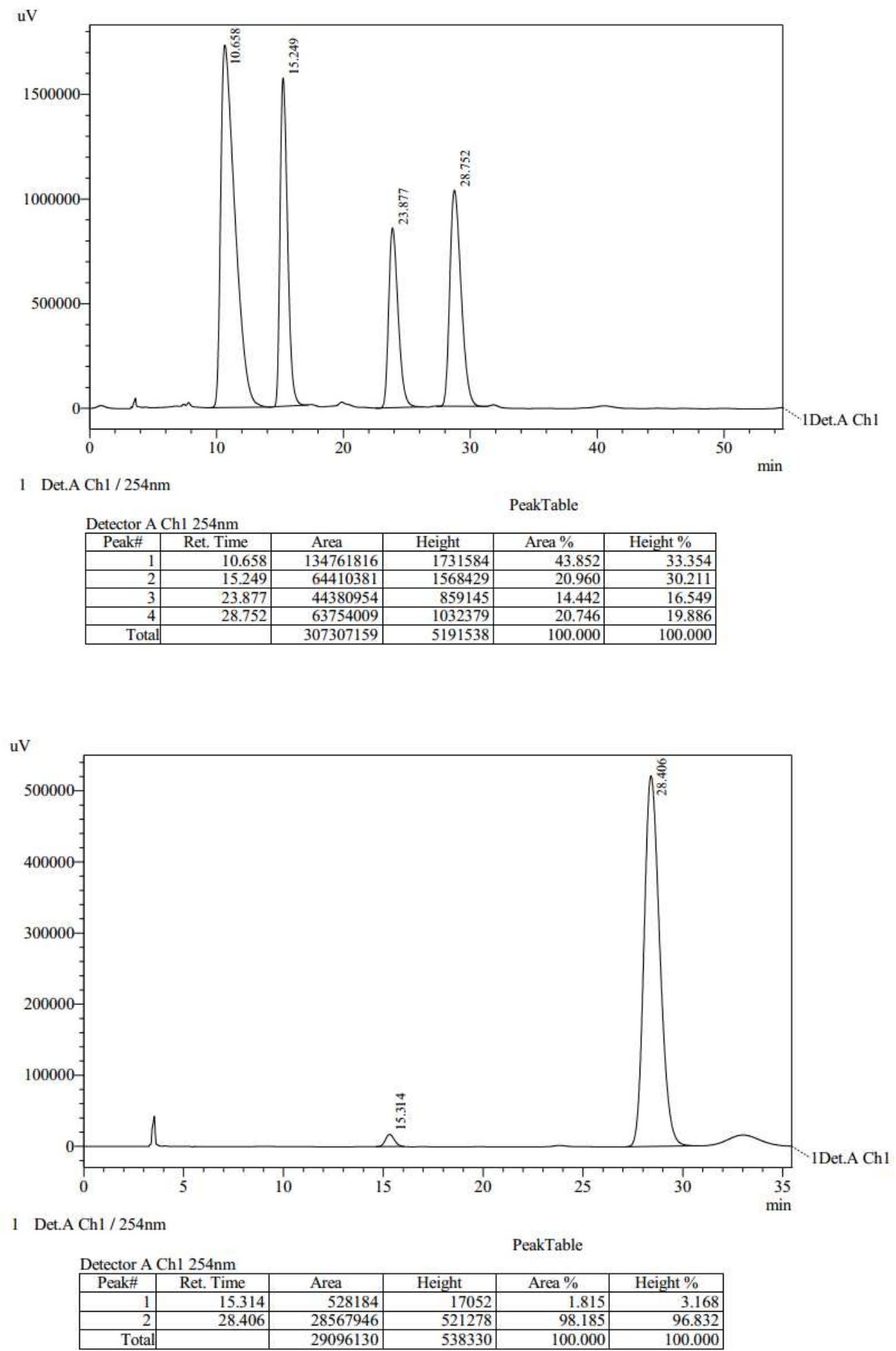
4 ec

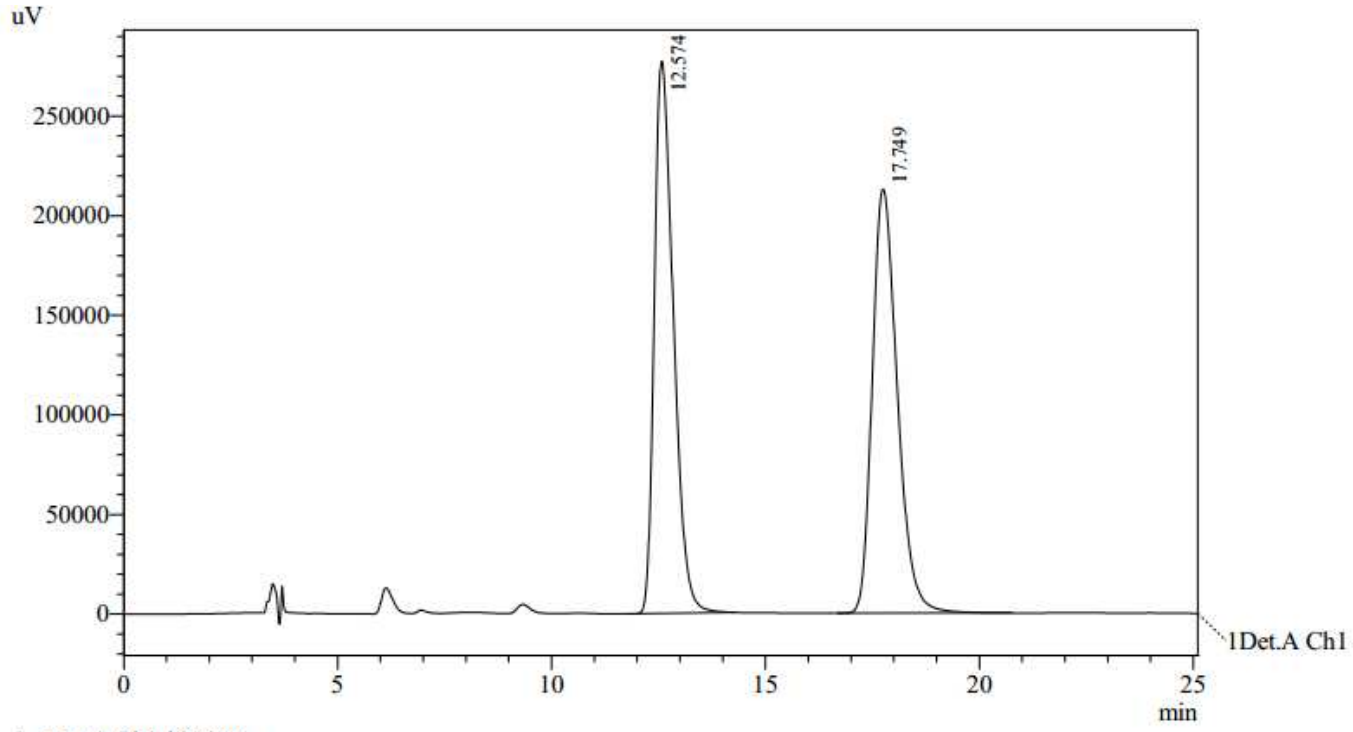

1 Det.A Ch1/254nm

Detector A Ch1 $254 \mathrm{~nm}$
\begin{tabular}{|r|r|r|r|r|r|}
\hline Peak\# & Ret. Time & \multicolumn{1}{c|}{ Area } & \multicolumn{1}{c|}{ Height } & Area $\%$ & \multicolumn{1}{c|}{ Height $\%$} \\
\hline 1 & 12.574 & 8598161 & 277153 & 49.812 & 56.564 \\
\hline 2 & 17.749 & 8663088 & 212825 & 50.188 & 43.436 \\
\hline Total & & 17261250 & 489978 & 100.000 & 100.000 \\
\hline
\end{tabular}

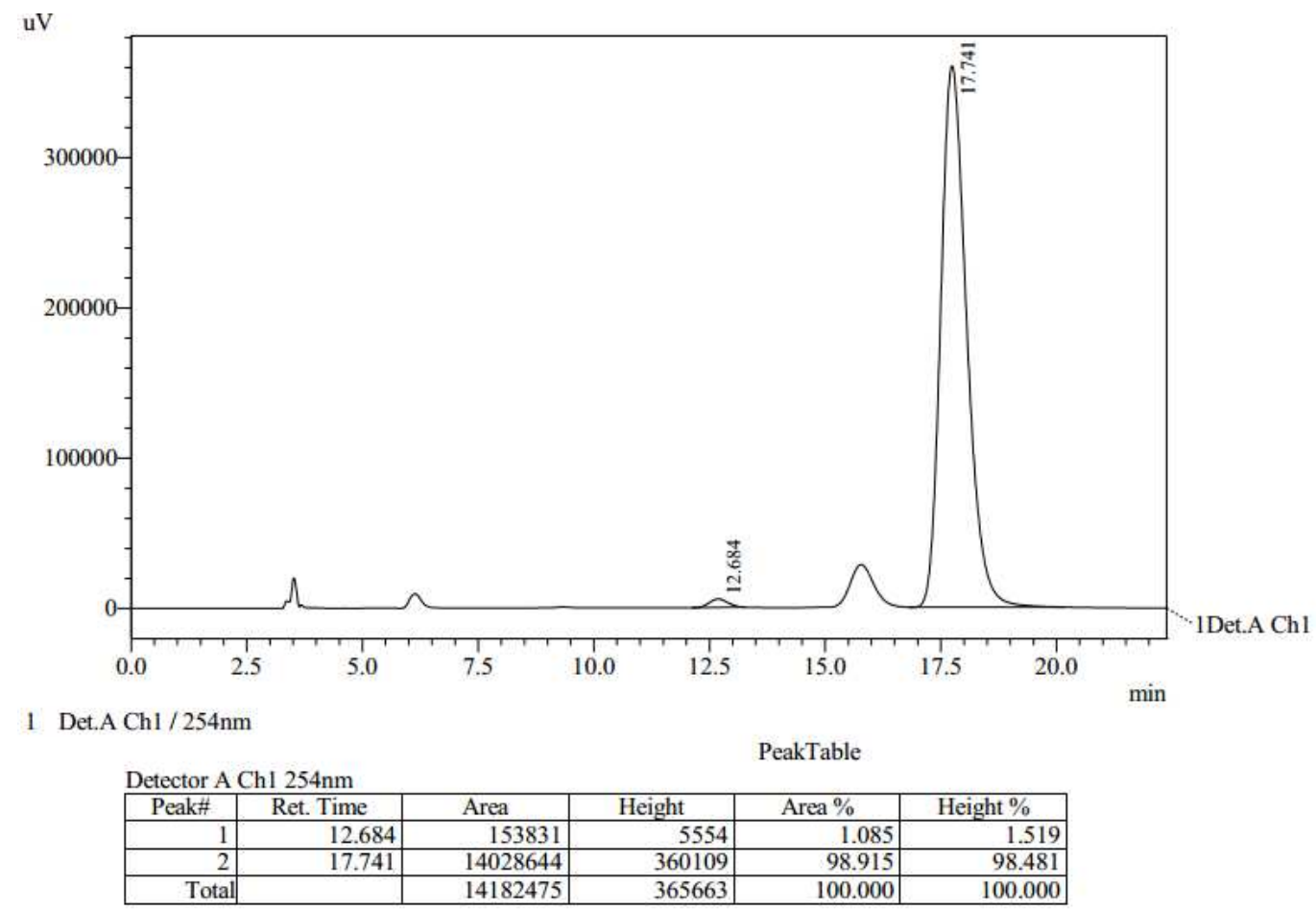


$41 a$

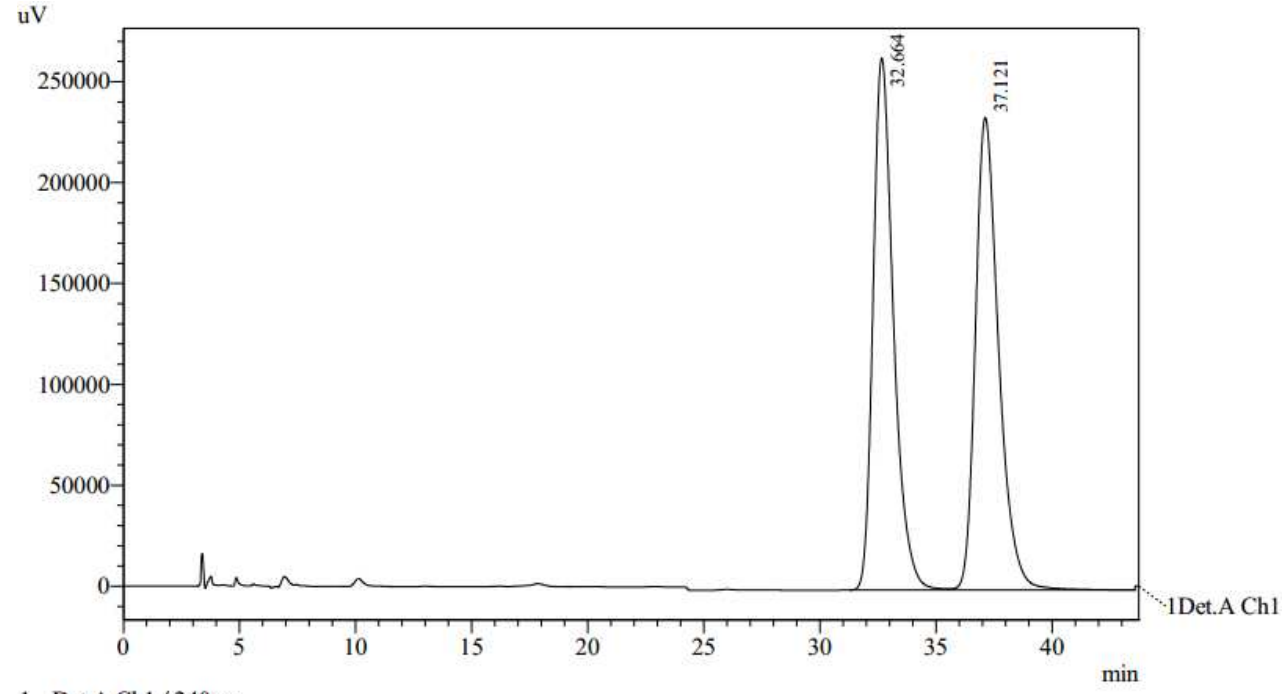

1 Det.A Chl / 240nm

Detector A Ch1 240nm
\begin{tabular}{|r|r|r|r|r|r|}
\hline \multicolumn{1}{|c|}{ Peak\# } & Ret. Time & \multicolumn{1}{|c|}{ Area } & Height & \multicolumn{1}{c|}{ Area $\%$} & Height $\%$ \\
\hline 1 & 32.664 & 16106727 & 263723 & 49.649 & 52.967 \\
\hline 2 & 37.121 & 16334623 & 234177 & 50.351 & 47.033 \\
\hline Total & & 32441350 & 497899 & 100.000 & 100.000 \\
\hline
\end{tabular}

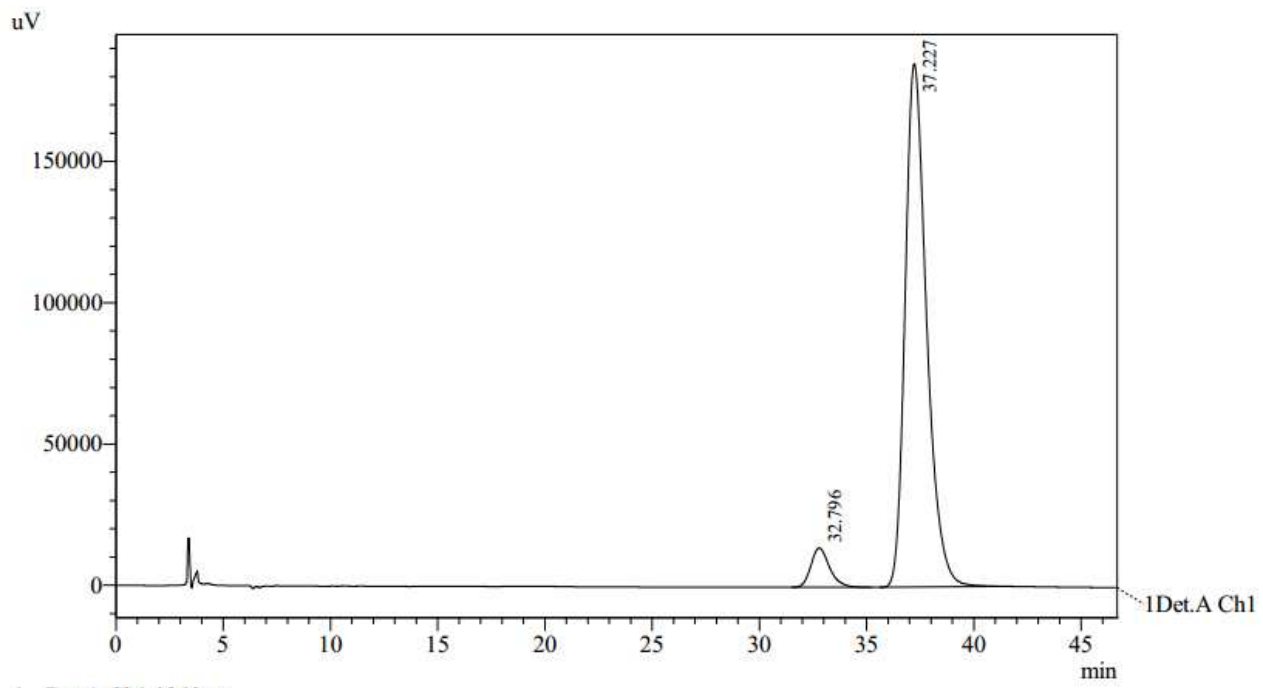

1 Det.A Ch1 / 240nm

Detector A Ch1 $240 \mathrm{~nm}$
\begin{tabular}{|r|r|r|r|r|r|}
\hline Peak\# & Ret. Time & Area & Height & Area $\%$ & \multicolumn{1}{c|}{ Height $\%$} \\
\hline 1 & 32.796 & 844308 & 13942 & 6.154 & 7.000 \\
\hline 2 & 37.227 & 12876142 & 185238 & 93.846 & 93.000 \\
\hline Total & & 13720450 & 199180 & 100.000 & 100.000 \\
\hline
\end{tabular}


4ma
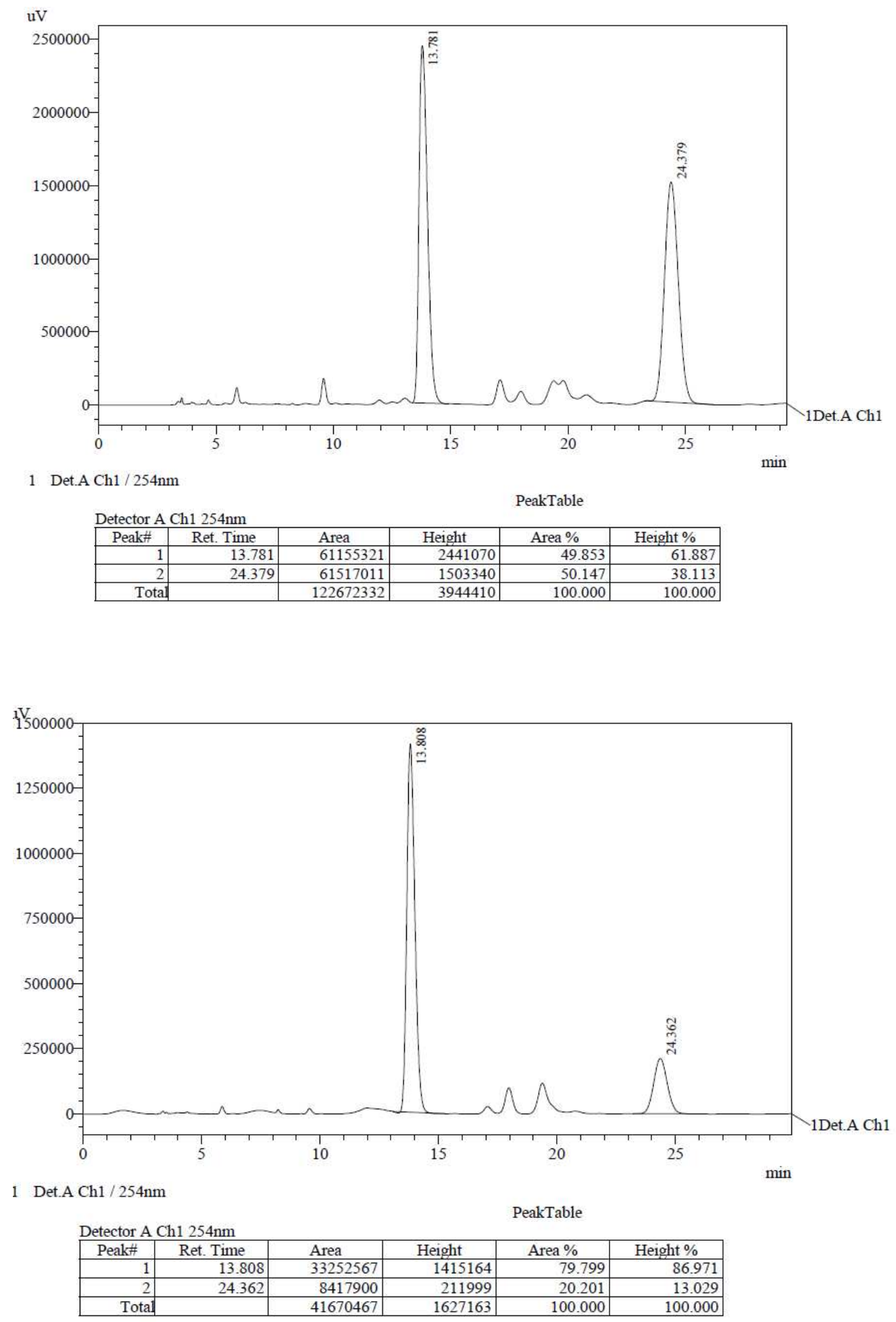


\section{X-ray data of racemic 4aa and enantiopure 4eb, Iaa}
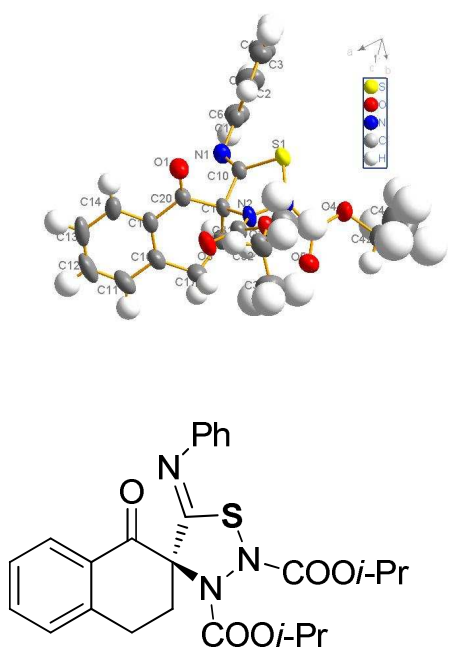

4aa
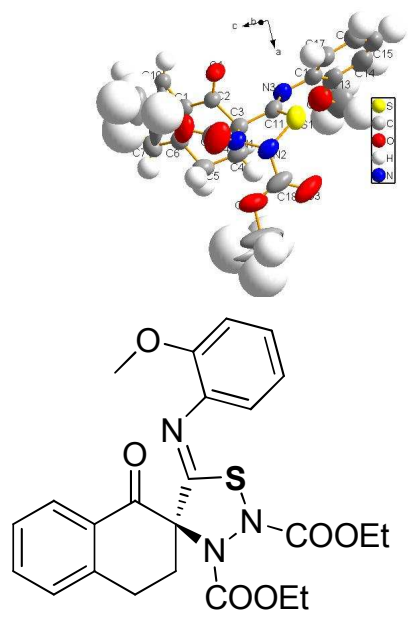

4eb
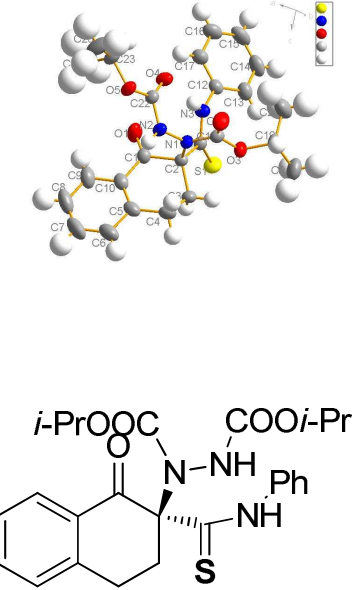

Iaa

Figure S1 Displacement ellipsoids are drawn at the $30 \%$ probability level

Crystal data for 4aa. $\mathrm{C}_{25} \mathrm{H}_{27} \mathrm{~N}_{3} \mathrm{O}_{5} \mathrm{~S}$ (481.56), Triclinic, $\mathrm{P}-1$; $\mathrm{a}=10.4968(3) \AA$, alpha $=76.6160(10)$ deg. $\mathrm{b}=$ 11.6056(3) $\AA$, beta $=70.0600(10)$ deg. $\mathrm{c}=12.3250(3) \AA$, gamma $=65.5420(10)$ deg. $U=1277.61(6) \AA^{3}, Z=2, T=$ $296(2) \mathrm{K}$, absorption coefficient $0.166 \mathrm{~mm}^{-1}$, reflections collected 43556, unique 5911 [R(int) $=0.0478$ ], refinement by Full-matrix least-squares on $F^{2}$, data/ restraints/ parameters $5911 / 0 / 296$, goodness-of-fit on $F^{2}=1.266$, final $R$ indices $[I>2 \operatorname{sigma}(I)] \mathrm{R} 1=0.0488, \mathrm{wR} 2=0.1595, R$ indices (all data) $\mathrm{R} 1=.0721, \mathrm{wR} 2=0.1842$, largest diff. peak and hole 0.421 and $-0.289 \mathrm{e} . \AA^{-3}$.

Crystal data for 4eb $\mathrm{C}_{25} \mathrm{H}_{27} \mathrm{~N}_{3} \mathrm{O}_{5} \mathrm{~S}$ (481.56), Orthorhombic, P2(1)2(1)2(1), a = 10.872(4) $\AA$, alpha $=90$ deg. b = 12.354(4) $\AA$, beta $=90$ deg. $\mathrm{c}=17.965(6) \AA$, gamma $=90$ deg. $U=2412.9(14) \AA^{3}, Z=31, T=296(2) \mathrm{K}$, absorption coefficient $0.178 \mathrm{~mm}^{-1}$, reflections collected 16849, unique 5538 [R(int) $\left.=0.0531\right]$, refinement by Full-matrix least-squares on $F^{2}$, data/ restraints/ parameters $5538 / 0 / 308$, goodness-of-fit on $F^{2}=1.004$, final $R$ indices $[I>2 \operatorname{sigma}(I)] \mathrm{R} 1=0.0584, \mathrm{wR} 2=0.1347, R$ indices $($ all data) $\mathrm{R} 1=0.1172, \mathrm{wR} 2=0.1662$, largest diff. peak and hole 0.286 and -0.214 e. $\AA^{-3}$.

Crystal data for Iaa $\mathrm{C}_{25} \mathrm{H}_{29} \mathrm{~N}_{3} \mathrm{O}_{5} \mathrm{~S}(483.57)$, mon $^{\circ}$ Clinic, Mon ${ }^{\circ}$ Clinic, $\quad$ P2(1), a = 8.6809(2) $\AA$, alpha $=90.00$ deg. b $=$ 14.1972(3) $\AA$, beta $=100.5210(10)$ deg. $\mathrm{c}=10.4181(3) \AA$, gamma $=90.00$ deg. $U=1262.39(5) \AA^{3}, Z=16, T=296(2)$ $\mathrm{K}$, absorption coefficient $0.168 \mathrm{~mm}^{-1}$, reflections collected 25042 , unique 5806 [R(int) $=0.0381$, refinement by Full-matrix least-squares on $F^{2}$, data/ restraints/ parameters $5806 / 1 / 308$, goodness-of-fit on $F^{2}=1.043$, final $R$ indices $[I>2 \operatorname{sigma}(I)] \mathrm{R} 1=0.0397, \mathrm{wR} 2=0.0810, R$ indices $($ all data) $\mathrm{R} 1=0.0397, \mathrm{wR} 2=0.0861$, largest diff. peak and hole 0.235 and $-0.235 \mathrm{e} . \AA^{-3}$. 